\title{
Deficiency in Silicon Uptake Affects Cytological, Physiological, and Biochemical Events in the Rice-Bipolaris oryzae Interaction
}

\author{
Leandro J. Dallagnol, Fabrício A. Rodrigues, Fábio M. DaMatta, Mateus V. B. Mielli, and Sandra C. Pereira
}

First, second, fourth, and fifth authors: Department of Plant Pathology, and third author: Department of Biology, Viçosa Federal University, Viçosa, Minas Gerais State, 36570-000, Brazil.

Accepted for publication 21 September 2010.

\begin{abstract}
Dallagnol, L. J., Rodrigues, F. A., DaMatta, F. M., Mielli, M. V. B., and Pereira, S. C. 2011. Deficiency in silicon uptake affects cytological, physiological, and biochemical events in the rice-Bipolaris oryzae interaction. Phytopathology 101:92-104.

This study investigated how a defect in the active uptake of silicon ( $\mathrm{Si}$ ) affects rice resistance to brown spot. Plants from a rice mutant (low silicon $1[l s i 1]$ ) and its wild-type counterpart (cv. Oochikara), growing in hydroponic culture with $(+\mathrm{Si} ; 2 \mathrm{mM})$ or without $(-\mathrm{Si}) \mathrm{Si}$, were inoculated with Bipolaris oryzae. Si concentration in leaf tissue of cv. Oochikara and the $l s i 1$ mutant increased by 381 and $263 \%$, respectively, for the $+\mathrm{Si}$ treatment compared with the $-\mathrm{Si}$ treatment. The incubation period was 6 $\mathrm{h}$ longer in the presence of $\mathrm{Si}$. The area under brown spot progress curve for plants from cv. Oochikara and the lsil mutant was reduced 81 and

$50 \%$, respectively, in the presence of $\mathrm{Si}$. The reduced number of brown epidermal cells on leaves from cv. Oochikara and the lsil mutant supplied with $\mathrm{Si}$ contributed to the lower lipid peroxidation and electrolyte leakage. The concentration of total soluble phenolics in cv. Oochikara supplied with $\mathrm{Si}$ (values of 4.2 to $15.4 \mu \mathrm{g} \mathrm{g}^{-1}$ fresh weight) was greater compared with plants not supplied with Si (values of 1.9 to $11.5 \mu \mathrm{g} \mathrm{g}^{-1}$ fresh weight). The concentration of lignin was also important to the resistance of cv. Oochikara and the lsil mutant. Polyphenoloxidase activity did not contribute to the resistance of $\mathrm{cv}$. Oochikara and the lsil mutant to brown spot, regardless of Si supply. Peroxidase and chitinase activities were higher in cv. Oochikara and the lsil mutant supplied with $\mathrm{Si}$. These results bring novel evidence of the involvement of Si in a more complex defense mechanism than simply the formation of a physical barrier to avoid or delay fungal penetration.
\end{abstract}

Brown spot, caused by Bipolaris oryzae (Breda de Haan) Shoemaker, is an economically important disease of rice because it negatively impacts grain quality and reduces yield by up to $74 \%$ (29). Light reddish-brown lesions or lesions with a gray center surrounded by a dark to reddish-brown margin with a bright yellow halo on leaf blades are the typical symptoms of this foliar disease (45). These symptoms appear no later than $18 \mathrm{~h}$ after the mycelium formed by the germinated conidium enters through stomata or penetrates directly into the epidermal cells (60). The nonselective toxins produced by $B$. oryzae quickly cause browning of the infected cells, which die and provide the necessary nutrients for massive fungal colonization of the leaf tissues (60). These toxins produced by $B$. oryzae, known as ophiobolins $\mathrm{A}$ and $\mathrm{B}$, are present in the fluids produced during conidial germination and also within the infected rice leaf cells (67). They can efficiently stimulate electrolyte leakage and glucose leakage, and increase both potassium leakage and efflux through a depolarization of the transmembrane electrical potential $(12,59)$. The main role played by these toxins in the pathogenesis of $B$. oryzae in rice is to suppress the host defense response, by decreasing the content of phenolics and affecting the activities of peroxidases and phenylalanine-ammonia-lyases (63).

Strategies for brown spot management are limited because commercial cultivars with high levels of resistance are not available to growers (45). Consequently, fungicide application and proper plant nutrition have been the major management strategies (45). It is known that rice plants grown on soils deficient in calcium, iron, magnesium, manganese, potassium, and silicon are more susceptible to brown spot $(27,32)$.

Corresponding author: F. A. Rodrigues; E-mail address: fabricio@ufv.br

doi:10.1094/PHYTO-04-10-0105

(c) 2011 The American Phytopathological Society
Some economically important diseases in rice, such as blast, sheath blight, stem rot, leaf scald, leaf blight, and grain discoloration $(6,14,15,27,28,49,50,54)$, and in wheat $(10,47)$ have been reduced in intensity by silicon ( $\mathrm{Si}$ ) application. The severity of brown spot in rice plants growing in a Si-deficient Histosol was dramatically reduced by the application of calcium silicate slag to the soil (16). Other investigators have also reported a reduction in brown spot severity by feeding Si to the plants $(18,44,58)$.

Rice requires large amounts of Si for vigorous growth and high production (39), and can accumulate this element in shoots at concentrations several times higher than macronutrients such as nitrogen, phosphorus, and potassium (53). Si is taken up by roots from the soil solution in the form of monosilicic acid $\left(\mathrm{H}_{4} \mathrm{SiO}_{4}\right)$ (57). Monosilicic acid is efficiently translocated to the shoot via the transpiration stream and is rapidly polymerized as silica (38). In rice, the Si transporter genes Lsil and Lsi2 are responsible for the high capacity of the lateral roots to take up Si from the soil solution (41). The gene Lsil is responsible for an influx transporter protein of monosilicic acid while the gene Lsi2 is an active efflux transporter protein, localized in both the root exodermis and endodermis (40). Gene Lsi6 is involved in Si distribution in rice shoots (68). Mutant plants with these genes, although possessing passive transport activity for $\mathrm{Si}$, have increased our knowledge about the importance of Si to rice physiology. Yield of the mutant plants can be dramatically reduced under field conditions due to insect attack and greater intensity of diseases (41). A reduced Si content in tissues of plants from the lsil mutant rice dramatically affected its basal level of resistance to brown spot, suggesting that a minimum $\mathrm{Si}$ concentration is needed for rice resistance to be most effective (14). According to Yoshida et al. (69), a thick layer of silica beneath the cuticle of rice leaves and sheaths is formed after the monosilicic acid is polymerized. This cuticle-Si double layer may be partially responsible for impeding pathogen penetration and, consequently, decreasing the number of 
lesions on leaf blades or increasing the incubation period as reported for the rice-Pyricularia grisea and rice-Rhizoctonia solani pathosystems $(50,54)$. However, the soluble $\mathrm{Si}$ in plant tissue may somehow be associated with an increase in rice resistance to infection by $P$. grisea through the increased production of phenolics (49) and phytoalexins (52), in addition to strongly activating some pathogenesis-related (PR) genes such as $P R-1$ and peroxidase (51).

The objective of this study was to investigate how a defect in the active uptake of Si by a rice mutant, in contrast to its wildtype counterpart, affects the cytological (number of brown epidermal cells and their degree of browning), physiological (lipid peroxidation and electrolyte leakage), and biochemical (concentrations of phenolics and lignin and activities of peroxidase, polyphenoloxidase, and chitinase) events commonly associated with host resistance to brown spot.

\section{MATERIALS AND METHODS}

Nutrient solution preparation. The nutrient solution was prepared based on Hoagland and Arnon (23) with some modifications. It included the following macronutrients: $1.0 \mathrm{mM}$ $\mathrm{KNO}_{3}, 0.25 \mathrm{mM} \mathrm{NH} \mathrm{H}_{2} \mathrm{PO}_{4}, 0.1 \mathrm{mM} \mathrm{NH} 4 \mathrm{Cl}, 0.5 \mathrm{mM} \mathrm{MgSO}_{4} \cdot$ $7 \mathrm{H}_{2} \mathrm{O}$, and $1.0 \mathrm{mM} \mathrm{Ca}\left(\mathrm{NO}_{3}\right) \cdot 4 \mathrm{H}_{2} \mathrm{O}$; and the following micronutrients: $0.30 \mu \mathrm{M} \mathrm{CuSO}_{4} \cdot 5 \mathrm{H}_{2} \mathrm{O}, 0.33 \mu \mathrm{M} \mathrm{ZnSO} \cdot 7 \mathrm{H}_{2} \mathrm{O}$, $11.5 \mu \mathrm{M} \mathrm{H}_{3} \mathrm{BO}_{3}, 3.5 \mu \mathrm{M} \mathrm{MnCl}_{2} \cdot 4 \mathrm{H}_{2} \mathrm{O}, 0.1 \mu \mathrm{M}\left(\mathrm{NH}_{4}\right) \cdot 6 \mathrm{Mo}_{7} \mathrm{O}_{2}$. $4 \mathrm{H}_{2} \mathrm{O}, 25 \mu \mathrm{M} \mathrm{FeSO} \mathrm{S}_{4} \cdot 7 \mathrm{H}_{2} \mathrm{O}$, and $25 \mu \mathrm{M}$ EDTA bisodic. Si was supplied as silicic acid, which was prepared by passing potassium silicate through cation-exchange resin (Amberlite IR-120B, $\mathrm{H}^{+}$ form) (Sigma-Aldrich, St. Louis) (37). The Si concentrations used were 0 or $2 \mathrm{mM}$. The $\mathrm{pH}$ of the nutrient solution was 5.6, and was not altered by the addition of silicic acid.

Rice growth. Rice seed from cv. Oochikara and the low silicon 1 (lsil) mutant were surface sterilized in $10 \%$ (vol/vol) $\mathrm{NaOCl}$ for $1.5 \mathrm{~min}$, rinsed in sterilized water for $3 \mathrm{~min}$, and germinated on distilled water-soaked germitest paper (Fisher Scientific Co., Pittsburgh) in a germination chamber at $25^{\circ} \mathrm{C}$ for 6 days. Germinated seedlings were transferred to plastic pots with one-half strength nutrient solution without the presence of $\mathrm{Si}$ for 2 days. After this period, plants were transferred to new plastic pots with 5 liters of nutrient solution prepared with or without Si. The nutrient solution, without aeration, was changed every 4 days. Electrical conductivity and the $\mathrm{pH}$ of the nutrient solution were checked daily. The $\mathrm{pH}$ was kept at $\approx 5.5$ by using $\mathrm{NaOH}$ or $\mathrm{HCl}$ (1 M) when needed.

Inoculation procedure. Plants were inoculated with $B$. oryzae after 35 days (emergence of the eighth leaf from the main tiller) (42) in hydroponic culture with the treatments. An isolate of $B$. oryzae (CNPAF-HO 82), obtained from symptomatic rice plants and provided by Dr. Anne Sitarama Prabhu (EMBRAPA-National Center for Rice and Beans Research, Goiânia, Goiás, Brazil) was used to inoculate the plants. This isolate was preserved on pieces of filter paper in glass vials with silica gel at $4^{\circ} \mathrm{C}$. Pieces of filter paper containing the fungus were transferred to petri dishes with potato dextrose agar (PDA). After 3 days, PDA plugs containing fungal mycelia were transferred to new petri dishes containing PDA. These petri dishes were kept in a growth chamber at $25^{\circ} \mathrm{C}$ with a 12-h photoperiod for 10 days. A conidial suspension of $B$. oryzae $\left(5 \times 10^{3}\right.$ conidia $\left.\mathrm{ml}^{-1}\right)$ was applied as a fine mist to the leaves of each plant until runoff using a VL Airbrush atomizer (Paasche Airbrush Co., Chicago). Gelatin (1\%, wt/vol) was added to the sterile water to aid conidial adhesion to the leaves. Immediately after inoculation, plants were transferred to a mist chamber at $25 \pm 2{ }^{\circ} \mathrm{C}$ with an initial 24 -h dark period. After this period, plants were incubated using a 12-h photoperiod under a photon irradiance of $\approx 225 \mu \mathrm{mol} \mathrm{m} \mathrm{m}^{-2} \mathrm{~s}^{-1}$ provided by cool-white fluorescent lamps. The relative humidity inside the mist chamber was $\approx 95 \pm 2 \%$ throughout the experiments. Noninoculated and inoculated plants were kept in separate mist chambers for the duration of the experiments.

Experimental design. A two-by-two-by-two factorial experiment, consisting of nutrient solution without and with $\mathrm{Si}(0$ and $2 \mathrm{mM}$, hereafter referred to $-\mathrm{Si}$ and $+\mathrm{Si}$ treatments, respectively), plant materials (rice cv. Oochikara and the lsil mutant), and noninoculated and inoculated plants was arranged in a completely randomized design with four replications. Each experimental unit consisted of one plastic pot with six plants.

Assessments. Incubation period and brown spot severity. The fifth and sixth leaves from the main tiller of each plant were marked and used to evaluate the incubation period (IP) (time in hours for the appearance of lesions on the leaves) and brown spot severity (BSS). The IP was scored by examining the marked leaves every $3 \mathrm{~h}$ after inoculation (hai). The BSS on marked leaves was scored at 48, 72, 96, 120, and 144 hai by using a scale based on the percentage of diseased leaf area (24). Area under brown spot progress curve (AUBSPC) for each leaf in each plant was computed using the trapezoidal integration of brown spot progress curve over time using the formula proposed by Shaner and Finney (55).

Cytological observations. In total, 30 to 50 leaf pieces $\left(\approx 1 \mathrm{~cm}^{2}\right.$ in size) were randomly collected from the fifth and sixth leaves in the main tiller of each plant per replication and treatment at 18, 24 , and 36 hai. Leaf pieces were fixed and decolorized in boiling $95 \%$ ethanol $(\mathrm{vol} / \mathrm{vol})$ for $\approx 15 \mathrm{~min}$ before being cleared for 2 weeks in saturated chloral hydrate solution $\left(50 \mathrm{~g} \mathrm{ml}^{-1}\right)$ (SigmaAldrich). Cleared leaf pieces were mounted adaxial side up on glass slides containing two to three drops of modified Hoyer's mounting medium (13). Fifty infection sites per replication and treatment were randomly examined to determine the number of brown epidermal cells and the degree of browning under a Carl Zeiss Axio Imager A1 microscope ( $\times 400$ magnification) (Carl Zeiss AG, Germany) equipped with differential interference contrast optics. The degree of browning of the 50 infection sites examined was grouped into three categories: $1=$ cell wall of epidermal cells showing no browning; $2=$ cell wall of epidermal cells palely yellowed or slightly brown; and 3 = whole-epidermal cells deeply browned, with adjacent cells showing slightly brown cell wall (51). The number of infection sites for each category was converted to percentage based on the total number of infection sites examined for the degree of browning.

Lipid peroxidation assay. In a separate experiment, seven leaf discs $\left(\approx 0.5 \mathrm{~cm}^{2}\right.$ in size $)$ were collected from the fourth, fifth, and sixth leaves of each plant per replication and treatment at 18, 36, 72 , and 144 hai with $B$. oryzae. Leaf discs collected from noninoculated plants served as a control (0 hai). Leaf samples were kept in liquid nitrogen during sampling and then stored at $-80^{\circ} \mathrm{C}$ until further analysis. Oxidative damage to lipids in the leaf cells was estimated as the content of total 2-thiobarbituric acid (TBA) reactive substances and expressed as equivalents of malondialdehyde (MDA) according to Cakmak and Horst (7) with few modifications. Briefly, leaf discs were homogenized in $2 \mathrm{ml}$ of $0.1 \%(\mathrm{wt} / \mathrm{vol})$ trichloracetic acid (TCA) solution at $4^{\circ} \mathrm{C}$. After centrifugation at $10,000 \times g$ for $15 \mathrm{~min}, 0.5 \mathrm{ml}$ of the supernatant was reacted with $1.5 \mathrm{ml}$ of TBA $(0.5 \%$ in $20 \%$ TCA) for $20 \mathrm{~min}$ in a boiling water bath. After this period, the reaction was stopped in an ice bath. Samples were centrifuged at 13,000 $\times g$ for $4 \mathrm{~min}$ and the absorbance of the supernatant was recorded at $532 \mathrm{~nm}$. The concentration of MDA formed in each sample was calculated by using the extinction coefficient of $155 \mathrm{mM}^{-1} \mathrm{~cm}^{-1}$ and expressed as MDA in micromoles per kilogram of fresh weight.

Electrolyte leakage assay. In a separate experiment, 21 leaf discs $\left(\approx 0.5 \mathrm{~cm}^{2}\right.$ in size) were collected from the fourth, fifth, and sixth leaves from the main tiller of each plant per replication and treatment at 48, 72, 96, 120, and 144 hai. Leaf discs collected from noninoculated plants served as a control (0 hai). The electro- 
lyte leakage (EL) was determined according to the methodology of Lima et al. (36) with few modifications. Leaf discs were thoroughly washed in deionized sterile water and then left to float on $60 \mathrm{ml}$ of deionized water in sealed glass vials for $4 \mathrm{~h}$ at $25^{\circ} \mathrm{C}$. After this period, the first value of conductivity (reading one) was obtained in a conductivity meter (Tecnopon $m \mathrm{CA}-150$; $\mathrm{MS}$ Tecnopon Instrumentação Científica, Brazil). Next, the vials were transferred to an oven for $2 \mathrm{~h}$ at $90^{\circ} \mathrm{C}$ to obtain a new value for conductivity (reading two). The EL, in percentage, was obtained by dividing the value for reading one by the value of reading two.

Determination of the concentration of total soluble phenolics and lignin and lignin-like phenolic polymers. Samples from the fourth and fifth leaves of each plant per replication and treatment were collected at $18,24,36,48,72$, and 96 hai with $B$. oryzae. Leaf samples were also collected from noninoculated plants at the same time points above. Leaves were kept in liquid nitrogen during sampling and then stored at $-80^{\circ} \mathrm{C}$ until further analysis. A representative sample of $0.1 \mathrm{~g}$ of leaf sample from each replication and treatment was ground into a fine powder in a mortar and pestle with liquid nitrogen. The fine powder was transferred to a microcentrifuge tube, homogenized with $1.5 \mathrm{ml}$ of $80 \%$ methanol, and extracted overnight on a rotary shaker $(150 \mathrm{rpm})$ at room temperature. The homogenate solution was protected from light oxidation by covering the microcentrifuge tube with aluminum foil. The dark-green methanolic extract was centrifuged at $12,000 \times g$ for $5 \mathrm{~min}$, and the supernatant was transferred to a new microcentrifuge tube and stored at $-20^{\circ} \mathrm{C}$. The residue was kept at $-20^{\circ} \mathrm{C}$ for further determination of lignin and lignin-like phenolic polymers. The method developed by Zieslin and Ben-Zaken (71) was used to determine the concentration of total soluble phenolics (TSP) with a few modifications. A volume of $150 \mu \mathrm{l}$ of $0.25 \mathrm{~N}$ Folin and Ciocalteau's phenol reagent (Sigma-Aldrich) was added to $150 \mu \mathrm{l}$ of the methanolic extract and the mixture was homogenized and kept at room temperature for $5 \mathrm{~min}$. Next, $150 \mu \mathrm{l}$ of $1 \mathrm{M} \mathrm{Na}_{2} \mathrm{CO}_{3}$ was added to the mixture, which was homogenized again and kept at room temperature for $10 \mathrm{~min}$. The mixture was further homogenized with $1 \mathrm{ml}$ of distilled water and kept at room temperature for $1 \mathrm{~h}$. The absorbance of the developed blue color of a representative sample $(500 \mu \mathrm{l})$ of the mixture from each replication and treatment was measured at $725 \mathrm{~nm}$. The concentration of TSP was expressed as milligrams of phenolics (in terms of catechol) per gram fresh weight.

A volume of $1.5 \mathrm{ml}$ of sterile distilled water was added to the residue obtained after extraction of TSP and, after homogenization, the mixture was centrifuged at $12,000 \times g$ for $5 \mathrm{~min}$. The supernatant was discarded and the residue was left to dry at $65^{\circ} \mathrm{C}$ overnight. The dried alcohol-insoluble residue, containing both true lignin and phenolic acids esterified to the cell walls, was used for determination of lignin (4). A volume of $1.5 \mathrm{ml}$ of a 1:10 solution of thioglycolic acid (Sigma-Aldrich) and $2 \mathrm{~N} \mathrm{HCl}$ was added to the dried residue. The microcentrifuge tube was shaken gently to hydrate the residue and then placed in boiling water $\left(\approx 100^{\circ} \mathrm{C}\right)$ for $4 \mathrm{~h}$. The microcentrifuge tube was cooled in ice in a $4^{\circ} \mathrm{C}$ cold room for $10 \mathrm{~min}$. The mixture was then centrifuged at $12,000 \times g$ for $10 \mathrm{~min}$, and the supernatant was discarded. The precipitate was washed with $1.5 \mathrm{ml}$ of sterile distilled water, then centrifuged at $10,000 \times g$ for $10 \mathrm{~min}$. After centrifugation, the supernatant was discarded, the precipitate was resuspended in $1.5 \mathrm{ml}$ of $0.5 \mathrm{~N} \mathrm{NaOH}$, and the mixture was agitated overnight at $150 \mathrm{rpm}$ in a rotary shaker at room temperature. In the next step, the mixture was centrifuged at $10,000 \times g$ for $10 \mathrm{~min}$ and the supernatant was transferred to a new microcentrifuge tube. After adding $200 \mu \mathrm{l}$ of concentrated $\mathrm{HCl}$ to the supernatant, the microcentrifuge tube was transferred to a $4^{\circ} \mathrm{C}$ cold room for $4 \mathrm{~h}$ to allow the lignin-thioglycolic acid (LTGA) derivatives to precipitate. Following centrifugation at $10,000 \times g$ for $10 \mathrm{~min}$, the supernatant was discarded and the orange-brown precipitate was dissolved in $2 \mathrm{ml}$ of $0.5 \mathrm{~N} \mathrm{NaOH}$. The absorbance of LTGA derivatives in the supernatant was measured at $280 \mathrm{~nm}$. The concentration of LTGA derivatives was expressed as milligrams per kilogram fresh weight by using lignin alkali, 2-hydroxypropyl ether (Sigma-Aldrich), as a standard.

Determination of enzymes activities. In a separate experiment, samples from the fourth and fifth leaves of each plant per replication and treatment were collected at 18, 24, 36, 48, 72, and 96 hai with $B$. oryzae. Leaf samples were also collected from noninoculated plants at the same time points above. Leaf samples were kept in liquid nitrogen during sampling and then stored at $-80^{\circ} \mathrm{C}$ until further analysis.

Enzyme extracts of peroxidase (POX) (EC 1.11.1.7) were prepared following the method of Peixoto (46) with minor modifications. A total of $1 \mathrm{~g}$ of fresh leaf segments was ground into a fine powder in a mortar and pestle with liquid nitrogen. The fine powder was homogenized in an ice bath in $20 \mathrm{ml}$ of $100 \mathrm{mM}$ potassium phosphate buffer ( $\mathrm{pH}$ 6.8) containing $1 \mathrm{mM}$ phenylmethylsulfonyl fluoride (PMSF), $1 \mathrm{mM}$ ethylenediaminetetraacetic acid (EDTA), and $200 \mathrm{mg}$ polyvynilpolypyrrolidone (PVPP). The homogenate was centrifuged at $12,000 \times g$ for $15 \mathrm{~min}$ at $4^{\circ} \mathrm{C}$ and the supernatant was used as crude enzyme extract. The POX activity was assayed following the colorimetric determination of pyrogallol oxidation according to Kar and Mishra (26). A substrate mixture containing $950 \mu$ of distilled

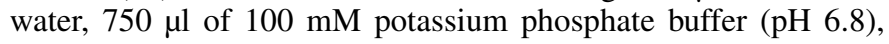
$600 \mu \mathrm{l}$ of $100 \mathrm{mM}$ pyrogallol, and $600 \mu \mathrm{l}$ of $100 \mathrm{mM}$ hydrogenous peroxide was added to $100 \mu \mathrm{l}$ of crude enzyme extract. Absorbance of the colored purpurogalin was recorded at $420 \mathrm{~nm}$ between the second and fifth minute after adding the crude enzyme extract to the substrate mixture. An extinction coefficient of $2.47 \mathrm{mM}^{-1}$ $\mathrm{cm}^{-1}$ was used to calculate POX activity (11). The POX activity was expressed as moles of purpurogalin produced per minute per milligram of protein.

Enzyme extracts of polyphenoloxidase (PPO) (EC 1.10.3.1) were prepared following the method of Peixoto (46) with minor modifications. In total, $0.5 \mathrm{~g}$ of fresh leaf segments was ground into a fine powder in a mortar and pestle with liquid nitrogen. The fine powder was homogenized in an ice bath in $5 \mathrm{ml}$ of $100 \mathrm{mM}$ potassium phosphate buffer ( $\mathrm{pH}$ 6.8) containing $1 \mathrm{mM}$ PMSF, $1 \mathrm{mM}$ EDTA, and $50 \mathrm{mg}$ of PVPP. The homogenate was centrifuged at $12,000 \times g$ for $15 \mathrm{~min}$ at $4^{\circ} \mathrm{C}$ and the supernatant was used as crude enzyme extract. PPO activity was determined the same as for POX activity, except that hydrogen peroxide was not used in the substrate mixture.

Enzyme extracts of chitinase (CHI) (EC 3.2.1.14) were prepared following the method of Lanna et al. (31). One gram of fresh leaf segments was ground into a fine powder in a mortar and pestle with liquid nitrogen. The fine powder was homogenized in an ice bath in $3 \mathrm{ml}$ of $50 \mathrm{mM}$ sodium phosphate buffer ( $\mathrm{pH} \mathrm{6.5)}$ containing $1 \mathrm{mM}$ PMSF and $30 \mathrm{mg}$ of PVPP. The homogenate was centrifuged at $20,000 \times g$ for $25 \mathrm{~min}$ at $4^{\circ} \mathrm{C}$ and the supernatant was used as crude enzyme extract. The $\mathrm{CHI}$ activity was assayed following the colorimetric determination of $p$-nitrophenyl cleaved from a chitin-analogous substrate $p$-nitrophenyl- $\beta$-D$N, N$ '-diacetylchitobiose (PNP) (Sigma-Aldrich) $(22,48)$. The reaction was started after the addition of $20 \mu \mathrm{l}$ of crude enzyme extract to a mixture containing $470 \mu \mathrm{l}$ of $50 \mathrm{mM}$ sodium acetate buffer ( $\mathrm{pH} \mathrm{5.0)}$ and $10 \mu \mathrm{l}$ of PNP at $2 \mathrm{mg} \mathrm{ml}^{-1}$. The reaction mixture was incubated in a water bath at $37^{\circ} \mathrm{C}$ for $2 \mathrm{~h}$. The reaction was terminated by adding $0.5 \mathrm{ml}$ of $0.2 \mathrm{M}$ sodium carbonate. Absorbance of the end products released by CHI present in the crude enzyme extract was recorded at $410 \mathrm{~nm}$. An extinction coefficient of $7 \times 10^{3} \mathrm{mM}^{-1} \mathrm{~cm}^{-1}$ was used to calculate $\mathrm{CHI}$ activity. The CHI activity was expressed as millimoles of $p$ nitrophenyl produced per minute per milligram of protein.

For each enzyme activity, three separate extractions were performed for samples from each treatment. Each extraction was 
read three times. A boiled extract was used as the blank treatment during the determination of each enzyme activity. The soluble protein contents of the extracts were measured by the method of Warburg and Christian (65).

Leaf tissue analysis for $\mathrm{Si}$ concentration. After the termination of the experiment carried out to evaluate the IP and the BSS, leaves were collected from plants of each replication for each treatment, washed in deionized water, dried for $72 \mathrm{~h}$ at $65^{\circ} \mathrm{C}$, and ground to pass through a 40-mesh screen with a ThomasWiley mill (Thomas Scientific, Swedesboro, NJ). Si concentration in leaf tissue was determined by a colorimetric analysis on $0.1 \mathrm{~g}$ of dried and alkali-digested tissue (14). Results obtained were expressed in dekagrams of Si per kilogram of dried leaf tissue.

Data analysis. One experiment was carried out to evaluate the variables IP, BSS, concentration of TSP and LTGA derivatives, and $\mathrm{Si}$ concentration. Lipid peroxidation, EL, and enzyme activities were studied in separate experiments. Experiments were repeated once. Data from each variable from the two experiments were pooled for statistical analysis because homogeneity of variances was confirmed by Cochran's test. Moreover, the experiment-treatment interactions were not significant $(P \geq 0.05)$ when compared with the main effects of treatments. Data from all evaluated variables were analyzed by analysis of variance and treatment mean comparisons by Tukey's test $(P \leq 0.05)$ or $t$ test using SAS (version 6.12; SAS Institute, Inc., Cary, NC).

\section{RESULTS}

$\mathrm{Si}$ concentration in rice leaf tissue. The factors $\mathrm{Si}$ concentration and plant material, as well as their interaction, were significant $(P \leq 0.05)$ (Table 1$)$. The leaf Si concentration from cv. Oochikara and the lsil mutant was significantly $(P \leq 0.05)$ increased by 381 and $263 \%$, respectively, for the $+\mathrm{Si}$ treatment compared with the $-\mathrm{Si}$ treatment (Fig. 1). For the $+\mathrm{Si}$ treatment, Si concentration from cv. Oochikara was $93 \%$ higher $(P \leq 0.05)$ than in the lsil mutant.

TABLE 1. Analysis of variance of the effects of silicon concentrations ( $\mathrm{Si}$ ) and plant materials (PM) on the variables $\mathrm{Si}$ in leaf tissue, incubation period (IP), and area under brown spot progress curve (AUBSPC)

\begin{tabular}{lcccc}
\hline & & \multicolumn{3}{c}{$F$ values $^{\mathrm{z}}$} \\
\cline { 3 - 5 } Sources of variation & df & $\mathrm{Si}(\%)$ & $\mathrm{IP}$ & AUBSPC \\
\hline $\mathrm{Si}$ & 1 & $5,983.38^{*}$ & $56.59^{*}$ & $149.83^{*}$ \\
$\mathrm{PM}$ & 1 & $1,233.24^{*}$ & $26.75^{*}$ & $7.19^{* *}$ \\
$\mathrm{Si} \times \mathrm{PM}$ & 1 & $723.66^{*}$ & $3.54 \mathrm{~ns}$ & $8.97^{*}$ \\
Replications & 7 & $1.09 \mathrm{~ns}$ & $1.23 \mathrm{~ns}$ & $1.62 \mathrm{~ns}$ \\
\hline
\end{tabular}

${ }^{\mathrm{z}}$ Levels of probability: $\mathrm{ns}=$ nonsignificant, $*=0.05$, and $* *=0.01$.

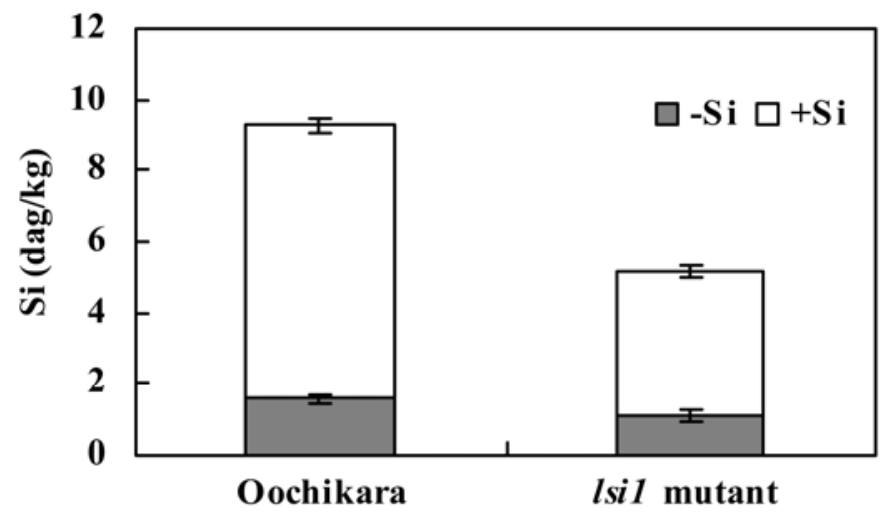

Fig. 1. Silicon concentration in dried leaf tissue of rice plants from cv. Oochikara and the lsil mutant grown in hydroponic culture containing 0 or $2 \mathrm{mM}$ silicon $(-\mathrm{Si}$ or $+\mathrm{Si}$, respectively). Error bars represent standard deviation of the means $(n=8)$.
IP and AUBSPC. For the IP, only the effects of Si concentration and plant material were significant $(P \leq 0.05)$ (Table 1). The IP significantly increased by $4 \mathrm{~h}$ for $\mathrm{cv}$. Oochikara compared with the lsil mutant. For the $+\mathrm{Si}$ treatment, the IP was $6 \mathrm{~h}$ longer than in the -Si treatment. For AUBSPC, the factors Si concentration and plant material, as well as their interaction, were significant $(P \leq 0.05)$ (Table 1$)$. Plants from cv. Oochikara and the lsil mutant in the + Si treatment showed significant reductions of 81 and $50 \%$, respectively, for AUBSPC compared with the $-\mathrm{Si}$ treatment (Table 2). There was no significant difference between cv. Oochikara and the lsil mutant in the -Si treatment. However, in the $+\mathrm{Si}$ treatment, AUBSPC was significantly reduced by $61 \%$ for cv. Oochikara compared with the lsil mutant.

Evaluation of cytological, physiological, and biochemical variables. Determination of the number of brown epidermal cells and the degree of browning. The factors $\mathrm{Si}$ concentration, plant material, and sampling time were significant $(P \leq 0.05)$ for number of brown epidermal cells (NBEC) and the three categories of browning epidermal cells as well as some interactions of these factors (Table 3). The NBEC dramatically increased from 18 to 36 hai for both cv. Oochikara and the lsil mutant in -Si and + Si treatments (Fig. 2). Interestingly, the NBEC was significantly lower in the $+\mathrm{Si}$ than in the $-\mathrm{Si}$ treatment $(P \leq 0.05)$ at 24 and 36 hai for cv. Oochikara and at 18, 24, and 36 hai for the lsil mutant (Fig. 2). At the infection sites examined, cell walls became pale yellow or slightly brown (category 2) at 18 hai for $\mathrm{cv}$. Oochikara in the -Si treatment and for the lsil mutant in both $-\mathrm{Si}$ and $+\mathrm{Si}$ treatments (Fig. 3). For cv. Oochikara in the $+\mathrm{Si}$ treatment, cell walls became pale yellow or slightly brown only at 36 hai. A decrease in the frequency of infection sites showing browning (category 2) by 24 hai was followed by an increase in the frequency of infection sites with whole epidermal cells deeply brown and adjacent cells with slightly brown cell walls (category 3 ) at 36 hai regardless of the treatments (Fig. 3). The frequency of infection sites showing browning (category 3) was lower in $+\mathrm{Si}$ than in the $-\mathrm{Si}$ treatment because of the high frequency of infection sites exhibiting either no browning of the epidermal cell walls (category 1) or pale yellow or slightly brown cell walls (category 2) (Fig. 3).

Lipid peroxidation. The factors Si concentration and sampling time, as well as some interactions of these factors, were significant $(P \leq 0.05)$ for MDA concentration (Table 4). The MDA concentration for both cv. Oochikara and the lsil mutant in the $-\mathrm{Si}$ treatment increased from 0 to 18 hai and then decreased at 36 hai, with stable values thereafter (Fig. 4). For cv. Oochikara in the $+\mathrm{Si}$ treatment, MDA concentration attained constant values from 0 to 36 hai and slightly increased thereafter. For the lsi 1 mutant in the $+\mathrm{Si}$ treatment, MDA concentration slightly increased from 0 to 36 hai and remained constant thereafter. The MDA concentration was significantly higher at 18 and 36 hai in the $-\mathrm{Si}$ treatment than in the $+\mathrm{Si}$ treatment for $\mathrm{cv}$. Oochikara and only at 18 hai for the lsil mutant (Fig. 4).

$E L$. The factor Si concentration and sampling time, as well as some interactions of these factors, were significant $(P \leq 0.05)$ for EL (Table 5). For cv. Oochikara in the -Si treatment, the EL increased from 0 to 144 hai but slightly increased over the same period in the $+\mathrm{Si}$ treatment (Fig. 5). The EL was significantly

TABLE 2. Area under brown spot progress curve on rice leaves from cv. Oochikara and the lsil mutant grown in hydroponic culture containing 0 or $2 \mathrm{mM}$ silicon $(-\mathrm{Si} \text { or }+\mathrm{Si} \text {, respectively })^{\mathrm{z}}$

\begin{tabular}{lcr}
\hline Plant materials & $-\mathrm{Si}$ & \multicolumn{1}{c}{$+\mathrm{Si}$} \\
\hline Oochikara & $2,397.38 \mathrm{aA}$ & $465.90 \mathrm{bB}$ \\
lsil mutant & $2,357.63 \mathrm{aA}$ & $1,185.68 \mathrm{bA}$ \\
\hline
\end{tabular}

${ }^{\mathrm{z}}$ Means within a column followed by the same uppercase letter or means within a row followed by the same lowercase letter are not significantly different $(P=0.05)$ as determined by Tukey's test. 
higher at 120 and 144 hai in the $-\mathrm{Si}$ treatment compared with $+\mathrm{Si}$ treatment for cv. Oochikara (Fig. 5). For the lsil mutant in the $-\mathrm{Si}$ treatment, EL remained constant from 0 to 96 hai and increased thereafter (Fig. 5). In the $+\mathrm{Si}$ treatment, EL reached stable values from 48 to 96 hai, increased at 120 hai, and remained constant thereafter.

Concentration of TSP and LTGA derivatives. The factors $\mathrm{Si}$ concentration, plant material, and sampling time were significant

TABLE 3. Analysis of variance of the effects of silicon concentrations ( $\mathrm{Si}$ ), plant materials (PM), and sampling times (ST) on the variables number of brown epidermal cells (NBEC) and degree of browning of epidermal cells (DBEC) for categories 1, 2, and 3

\begin{tabular}{|c|c|c|c|c|c|}
\hline \multirow[b]{2}{*}{ Sources of variation } & \multirow[b]{2}{*}{ df } & \multicolumn{4}{|c|}{$F$ values $^{\mathrm{z}}$} \\
\hline & & NBEC & DBEC 1 & DBEC 2 & DBEC 3 \\
\hline $\mathrm{Si}$ & 1 & $275.05^{*}$ & $579.77 *$ & $173.32 *$ & $1374.02 *$ \\
\hline PM & 1 & $20.01 *$ & $30.71 *$ & $73.29 *$ & $1422.62 *$ \\
\hline ST & 2 & $159.52 *$ & $2,793.72 *$ & $630.64 *$ & $2,1461.90 *$ \\
\hline $\mathrm{Si} \times \mathrm{PM}$ & 1 & $27.25^{*}$ & $220.95 *$ & $90.66^{*}$ & $362.54 *$ \\
\hline $\mathrm{Si} \times \mathrm{ST}$ & 2 & $12.84 *$ & $201.82 *$ & $232.25^{*}$ & $358.54 *$ \\
\hline $\mathrm{PM} \times \mathrm{ST}$ & 2 & $0.12 \mathrm{~ns}$ & $2.63 \mathrm{~ns}$ & $41.04 *$ & $419.28 *$ \\
\hline $\mathrm{Si} \times \mathrm{PM} \times \mathrm{ST}$ & 2 & $1.60 \mathrm{~ns}$ & $72.96 *$ & $55.51 *$ & $157.84 *$ \\
\hline Replications & 7 & $0.68 \mathrm{~ns}$ & $0.41 \mathrm{~ns}$ & $0.90 \mathrm{~ns}$ & $1.43 \mathrm{~ns}$ \\
\hline
\end{tabular}

${ }^{\mathrm{z}}$ Levels of probability: $\mathrm{ns}=$ nonsignificant and $*=0.05$.

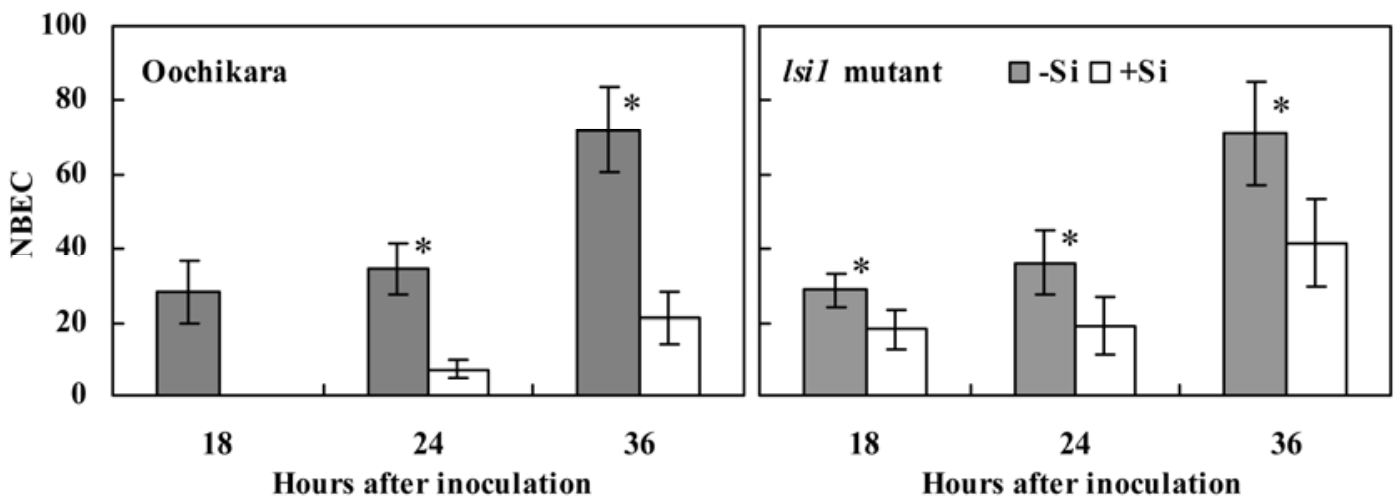

Fig. 2. Number of brown epidermal cells (NBEC) on rice leaves from plants from cv. Oochikara and the lsil mutant grown in hydroponic culture containing 0 or $2 \mathrm{mM}$ silicon $(-\mathrm{Si}$ or $+\mathrm{Si}$, respectively). Error bars represent standard deviation of the means $(n=8)$. Means from $-\mathrm{Si}$ and $+\mathrm{Si}$ treatments followed by an asterisk $(*)$ are different $(P \leq 0.05)$ by $t$ test.

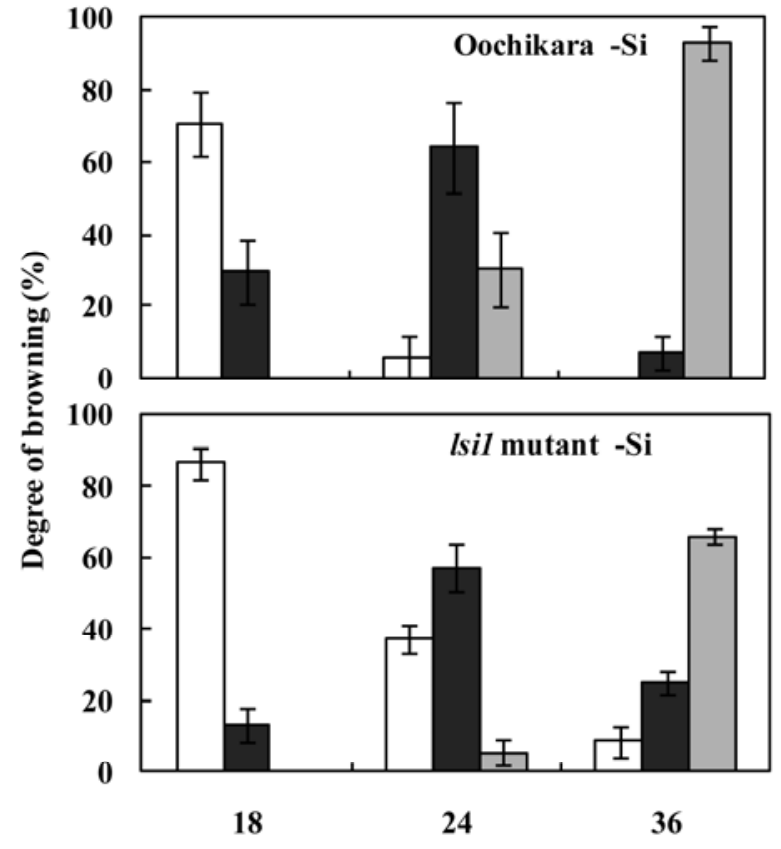

Hours after inoculation
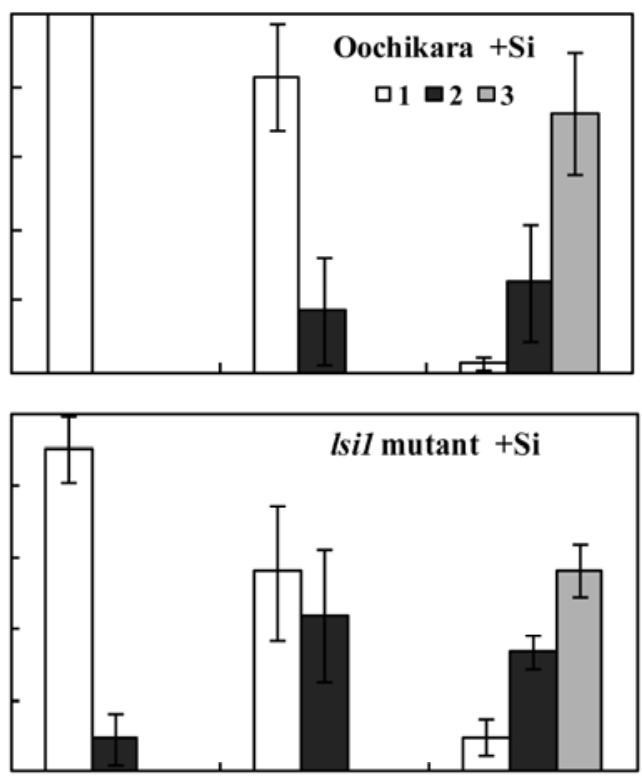

18
36

Fig. 3. Degree of browning of epidermal cells of rice plants from cv. Oochikara and the $l s i 1$ mutant grown in hydroponic culture containing 0 or $2 \mathrm{mM}$ silicon (-Si or $+\mathrm{Si}$, respectively). The degree of browning was grouped into three categories: $1=$ cell wall of epidermal cells showing no browning; $2=$ cell wall of epidermal cells palely yellowed or slightly brown; and $3=$ whole-epidermal cells deeply browned, with adjacent cells showing slightly browned cell wall. Number of infection sites for each category was converted to percentage based on the total number of infection sites examined (50) for the degree of browning. Error bars represent standard deviation of the means. 
$(P \leq 0.05)$ for concentration of TSP and LTGA derivatives (Table 6). Plant inoculation was not significant only for concentration of LTGA derivatives. Some two- or three-factor interaction effects were also significant (Table 6). The concentration of TSP decreased from 18 to 36 hai, peaked at 48 hai, and declined at 72 hai, with an increase onward for cv. Oochikara and the lsil mutant in both $-\mathrm{Si}$ and $+\mathrm{Si}$ treatments regardless of plant inoculation (Fig. 6). The concentration of TSP was significantly higher only at 18 hai in noninoculated plants compared with inoculated plants of cv. Oochikara in the -Si treatment. Significant differences for the concentration of TSP between noninoculated and inoculated plants of the $l$ sil mutant occurred only at 24 hai for the -Si treatment and at 24, 36, and 72 hai for the +Si treatment (Fig. 6). Differences between noninoculated and inoculated plants of cv. Oochikara occurred only at 48 hai for the $-\mathrm{Si}$ treatment. For the lsil mutant, differences occurred at 24 hai for the $-\mathrm{Si}$ treatment and at 24, 36, and 72 hai for the +Si treatment.

For noninoculated plants of $\mathrm{cv}$. Oochikara in the -Si treatment, the concentration of LTGA derivatives peaked at 36 hai and sharply decreased thereafter (Fig. 7). For inoculated plants, the concentration of LTGA derivatives peaked at 24 hai, decreased at 36 hai, and peaked again at 96 hai. Significant differences between noninoculated and inoculated plants occurred at 24, 36, and 96 hai. In the $+\mathrm{Si}$ treatment for noninoculated plants of $\mathrm{cv}$. Oochikara, the concentration of LTGA derivatives increased from 18 to 36 hai, decreased at 48 hai, and attained constant values from 72 to 96 hai (Fig. 7). For inoculated plants, the concentration of LTGA derivatives increased from 18 to 36 hai, decreased from 48 to 72 hai, and attained constant values thereafter. Significant differences between noninoculated and inoculated plants occurred at 72 and 96 hai (Fig. 7). The concentration of LTGA derivatives for noninoculated plants of the lsil mutant in the $-\mathrm{Si}$ treatment increased from 18 to 48 hai, decreased at 72 hai, and slightly increased thereafter (Fig. 7). For inoculated plants,

TABLE 4. Analysis of variance of the effects of silicon concentrations (Si), plant materials (PM), and sampling times (ST) on the concentration of malondialdehyde

\begin{tabular}{lcc}
\hline Sources of variation & df & $F$ values $^{\mathrm{z}}$ \\
\hline $\mathrm{Si}$ & 1 & $35.00^{*}$ \\
$\mathrm{PM}$ & 1 & $0.01 \mathrm{~ns}$ \\
$\mathrm{ST}$ & 4 & $23.78^{*}$ \\
$\mathrm{Si} \times \mathrm{PM}$ & 1 & $10.92^{*}$ \\
$\mathrm{Si} \times \mathrm{ST}$ & 4 & $19.99^{*}$ \\
$\mathrm{PM} \times \mathrm{ST}$ & 4 & $2.61^{* *}$ \\
$\mathrm{Si} \times \mathrm{PM} \times \mathrm{ST}$ & 4 & $0.86 \mathrm{~ns}$ \\
Replications & 7 & $1.11 \mathrm{~ns}$ \\
\hline
\end{tabular}

${ }^{\mathrm{z}}$ Levels of probability: $\mathrm{ns}=$ nonsignificant, $*=0.05$, and $* *=0.01$. the concentration of LTGA derivatives increased from 18 to 24 hai, remained constant from 24 to 72 hai, and decreased thereafter. In the $+\mathrm{Si}$ treatment for noninoculated plants, the concentration of LTGA derivatives decreased from 18 to 36 hai, peaked at 48 hai, and sharply decreased thereafter (Fig. 7). For inoculated plants, the concentration of LTGA derivatives showed the same trend as for noninoculated plants but increased at 96 hai (Fig. 7). Differences between noninoculated and inoculated plants of $\mathrm{cv}$. Oochikara occurred at 24, 36, and 96 hai for the -Si treatment and at 72 and 96 hai for the $+\mathrm{Si}$ treatment. There were no significant differences between noninoculated and inoculated plants of the lsil mutant regardless of Si treatments.

Enzymes activities. The factors Si concentration, plant material, sampling time, and plant inoculation were significant $(P \leq 0.05)$ for POX, PPO, and CHI activities (Table 6). Some two- or threefactor interaction effects were also significant (Table 6). For noninoculated plants of $\mathrm{cv}$. Oochikara in the $-\mathrm{Si}$ treatment, POX activity increased from 18 to 48 hai and attained constant values thereafter (Fig. 8). For inoculated plants, POX activity increased from 18 to 48 hai, decreased at 72 hai, and increased thereafter. The POX activity for noninoculated plants of cv. Oochikara in the $+\mathrm{Si}$ treatment increased from 18 to 24 hai and dramatically decreased thereafter (Fig. 8). For inoculated plants, POX activity increased from 18 to 36 hai, decreased at 48 hai, and slightly increased thereafter. For cv. Oochikara, significant differences between noninoculated and inoculated plants occurred at 36, 48, 72 , and 96 hai for the -Si treatment and for all sampling times at the $+\mathrm{Si}$ treatment except at 18 hai, with the highest values for POX activity occurring for inoculated plants. For noninoculated plants of the lsil mutant in both $-\mathrm{Si}$ and $+\mathrm{Si}$ treatments, regardless of plant inoculation, POX activity increased from 18 to 36 hai, decreased thereafter, and attained constant values from 72 to 96 hai (Fig. 8). Significant differences between noninoculated and inoculated plants of the $l s i 1$ mutant occurred at $24,48,72$, and 96 hai for the -Si treatment and at 36, 72, and 96 hai for the $+\mathrm{Si}$ treatment, with the highest values for POX activity occurring

TABLE 5. Analysis of variance of the effects of silicon concentrations (Si), plant materials (PM), and sampling times (ST) on the electrolyte leakage

\begin{tabular}{lcc}
\hline Sources of variation & df & $F$ values $^{\mathrm{z}}$ \\
\hline $\mathrm{Si}$ & 1 & $67.66^{*}$ \\
$\mathrm{PM}$ & 1 & $2.17 \mathrm{~ns}$ \\
$\mathrm{ST}$ & 5 & $32.34^{*}$ \\
$\mathrm{Si} \times \mathrm{PM}$ & 1 & $0.10 \mathrm{~ns}$ \\
$\mathrm{Si} \times \mathrm{ST}$ & 5 & $5.15^{*}$ \\
$\mathrm{PM} \times \mathrm{ST}$ & 5 & $1.14 \mathrm{~ns}$ \\
$\mathrm{Si} \times \mathrm{PM} \times \mathrm{ST}$ & 5 & $0.90 \mathrm{~ns}$ \\
Replications & 7 & $0.41 \mathrm{~ns}$ \\
\hline
\end{tabular}

${ }^{\mathrm{z}}$ Levels of probability: $\mathrm{ns}=$ nonsignificant and $*=0.05$.
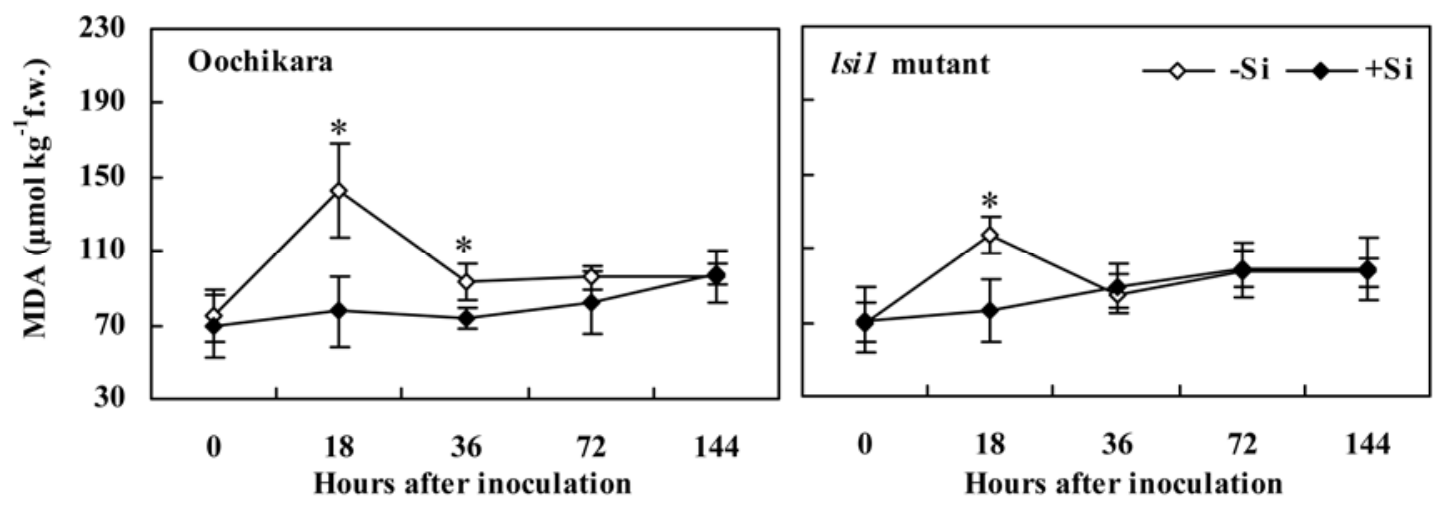

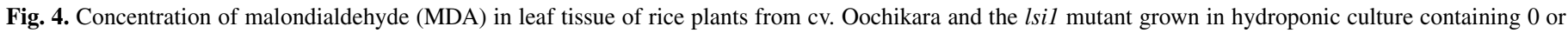

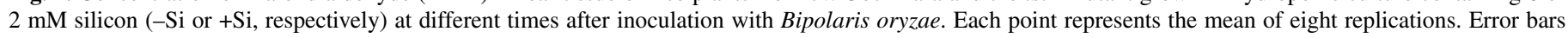
represent standard deviation of the means. Means from $-\mathrm{Si}$ and $+\mathrm{Si}$ treatments followed by an asterisk $(*)$ are different $(P \leq 0.05)$ by $t$ test; fw $=$ fresh weight. 
for inoculated plants. Differences between noninoculated and inoculated plants of cv. Oochikara occurred at 36, 48, 72, and 96 hai for the -Si treatment and at 24, 36, 48, 72, and 96 hai for the $+\mathrm{Si}$ treatment. For the lsil mutant, differences occurred at 24, 48, and 96 hai for the -Si treatment and at 36, 48, 72, and 96 hai for the $+\mathrm{Si}$ treatment.

For noninoculated plants of $\mathrm{cv}$. Oochikara in the -Si treatment, PPO activity decreased from 18 to 24 hai, increased at 36 hai, followed by a decrease, and then attained constant values from 72 to 96 hai (Fig. 9). For inoculated plants, PPO activity increased from 18 to 24 hai, decreased at 36 hai, followed by an increase until 72 hai, and sharply decreased thereafter. The PPO activity for noninoculated plants of $\mathrm{cv}$. Oochikara in the $+\mathrm{Si}$ treatment increased from 18 to 24 hai, dramatically decreased until 48 hai, and then attained constant values thereafter (Fig. 9). For inoculated plants, PPO activity attained constant values from 18 to 48 hai, peaked at 72 hai, and slightly increased thereafter. For noninoculated plants of the $l$ sil mutant in the -Si treatment, PPO activity decreased from 18 to 24 hai, increased at 36 hai, and sharply decreased thereafter (Fig. 9). For inoculated plants, PPO activity increased from 18 to 24 hai, decreased at 36 hai, followed by an increase until 72 hai, and dramatically decreased thereafter. The PPO activity for noninoculated and inoculated plants of the lsil mutant in the + Si treatment was kept stable from 18 to 36 hai. For noninoculated plants, PPO activity decreased at 48 hai, with stable values thereafter. On the other hand, for inoculated plants, PPO activity increased from 48 to 72 hai and attained constant values thereafter. Differences between noninoculated and inoculated plants of cv. Oochikara occurred at 24, 48, 72, and 96 hai for the -Si treatment and at 24, 36, 72, and 96 hai for the +Si treatment. For the lsil mutant, differences occurred at 18, 26, and 72 hai for the -Si treatment and at 36, 72, and 96 hai for the +Si treatment.

For both noninoculated and inoculated plants of cv. Oochikara in the -Si treatment, CHI activity was kept stable from 18 to 96 hai (Fig. 10). The CHI activity for noninoculated plants of cv. Oochikara in the $+\mathrm{Si}$ treatment slightly increased from 18 to 24 hai and reached constant values thereafter. For cv. Oochikara, significant differences between noninoculated and inoculated plants occurred at 24, 36, 72, and 96 hai in the -Si treatment and at $18,24,48,72$, and 96 hai in the + Si treatment, with the highest values occurring for inoculated plants. The $\mathrm{CHI}$ activity for both noninoculated and inoculated plants of the lsil mutant in the $-\mathrm{Si}$ treatment was kept stable from 18 to 96 hai, except for a peak at 72 hai for inoculated plants (Fig. 10). For both noninoculated and inoculated plants in the $+\mathrm{Si}$ treatment, $\mathrm{CHI}$ activity attained constant values from 18 to 36, and sharply decreased and increased, respectively, thereafter. Significant differences between noninoculated and inoculated plants of the $l s i l$ mutant occurred at 72 hai for the -Si treatment and at 48, 72, and 96 hai for the $+\mathrm{Si}$ treatment, with most of the highest values for CHI activity occurring for inoculated plants. Differences between noninoculated and inoculated plants of cv. Oochikara occurred at 24, 36, 72, and 96 hai for the -Si treatment and at 18, 24, 36, 48, 72, and 96 hai for the + Si treatment. For the lsil mutant, differences
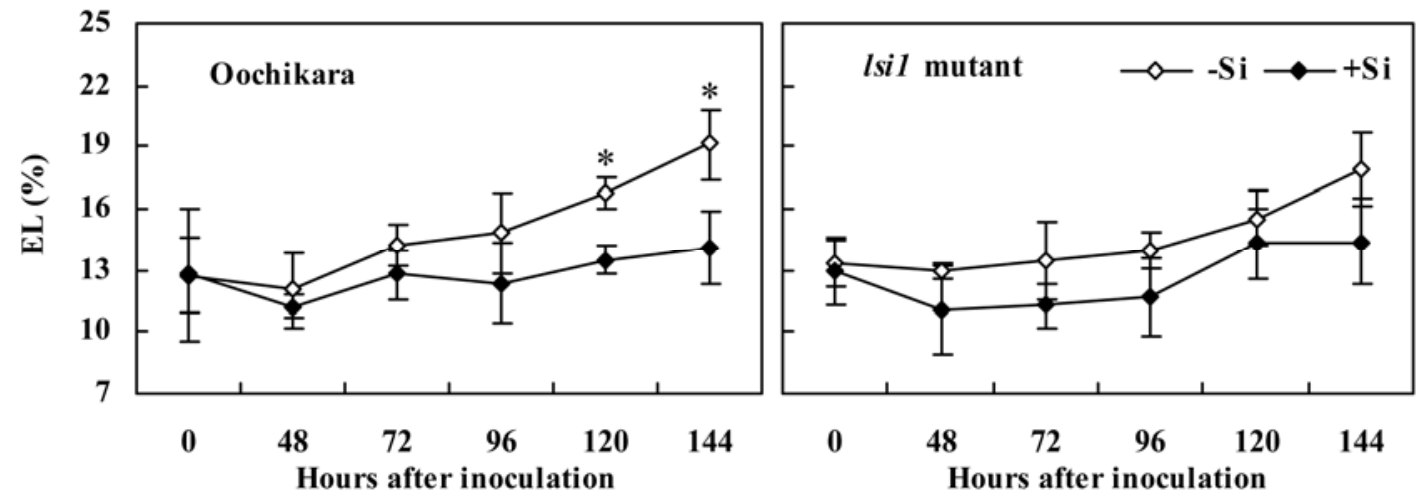

Fig. 5. Electrolyte leakage (EL) in leaf tissue of rice plants from cv. Oochikara and the $l s i 1$ mutant grown in hydroponic culture containing 0 or $2 \mathrm{mM}$ silicon (-Si or $+\mathrm{Si}$, respectively) at different times after inoculation with Bipolaris oryzae. Each point represents the mean of eight replications. Error bars represent standard deviation of the means. Means from $-\mathrm{Si}$ and $+\mathrm{Si}$ treatments followed by an asterisk $(*)$ are different $(P \leq 0.05)$ by $t$ test.

TABLE 6. Analysis of variance of the effects of silicon concentrations (Si), plant materials (PM), sampling times (ST), and plant inoculation (PI) on the variables concentrations of total soluble phenolics (TSP) and lignin-thioglycolic acid (LTGA) derivatives, as well as on the activity of the enzymes peroxidase (POX), polyphenoloxidase (PPO), and chitinase (CHI)

\begin{tabular}{|c|c|c|c|c|c|c|}
\hline \multirow[b]{2}{*}{ Sources of variation } & \multirow[b]{2}{*}{ df } & \multicolumn{5}{|c|}{$F$ values $^{\mathrm{z}}$} \\
\hline & & TSP & LTGA & POX & PPO & $\mathrm{CHI}$ \\
\hline $\mathrm{Si}$ & 1 & $9.94 *$ & $240.74^{*}$ & $147.96^{*}$ & $3.72 *$ & $632.71 *$ \\
\hline PM & 1 & $78.88^{*}$ & $141.05^{*}$ & $3,198.99 *$ & $17.70 *$ & $10.49 *$ \\
\hline ST & 5 & $1,004.04 *$ & $6.46^{*}$ & $1,623.92 *$ & $47.51 *$ & $96.15 *$ \\
\hline PI & 1 & $34.49 *$ & $2.67 \mathrm{~ns}$ & $3,653.32 *$ & $14.93 *$ & $2,229.76^{*}$ \\
\hline $\mathrm{Si} \times \mathrm{PM}$ & 1 & $71.58 *$ & $29.57 *$ & $59.95 *$ & $139.53 *$ & $11.08 *$ \\
\hline $\mathrm{Si} \times \mathrm{ST}$ & 5 & $15.72 *$ & $5.63^{*}$ & $511.69 *$ & $40.96 *$ & $107.17 *$ \\
\hline $\mathrm{Si} \times \mathrm{PI}$ & 1 & $0.02 \mathrm{~ns}$ & $10.89^{*}$ & $232.81 *$ & $0.94 \mathrm{~ns}$ & $295.30 *$ \\
\hline $\mathrm{PM} \times \mathrm{ST}$ & 5 & $15.77 *$ & $5.97 *$ & $777.66^{*}$ & $16.07 *$ & $42.44 *$ \\
\hline $\mathrm{PM} \times \mathrm{PI}$ & 1 & $19.08 *$ & $0.12 \mathrm{~ns}$ & $8.79 *$ & $46.46^{*}$ & $43.51 *$ \\
\hline $\mathrm{ST} \times \mathrm{PI}$ & 5 & $1.75 \mathrm{~ns}$ & $6.65^{*}$ & $523.70 *$ & $262.89 *$ & $146.28 *$ \\
\hline $\mathrm{Si} \times \mathrm{PM} \times \mathrm{ST}$ & 5 & $15.72 *$ & $9.99 *$ & $342.23 *$ & $56.69 *$ & $32.93 *$ \\
\hline $\mathrm{Si} \times \mathrm{PM} \times \mathrm{PI}$ & 1 & $29.59 *$ & $1.44 \mathrm{~ns}$ & $16.85^{*}$ & $499.42 *$ & $2.18 \mathrm{~ns}$ \\
\hline $\mathrm{Si} \times \mathrm{ST} \times \mathrm{PI}$ & 5 & $4.33^{*}$ & $12.74 *$ & $72.67 *$ & $92.67 *$ & $140.83^{*}$ \\
\hline $\mathrm{PM} \times \mathrm{ST} \times \mathrm{PI}$ & 5 & $4.94 *$ & $5.63^{*}$ & $151.60 *$ & $21.88 *$ & $67.32 *$ \\
\hline $\mathrm{Si} \times \mathrm{PM} \times \mathrm{ST} \times \mathrm{PI}$ & 5 & $6.15^{*}$ & $7.70 *$ & $78.31 *$ & $32.65 *$ & $84.58 *$ \\
\hline Replications & 7 & $0.60 \mathrm{~ns}$ & $1.16 \mathrm{~ns}$ & $0.07 \mathrm{~ns}$ & $0.23 \mathrm{~ns}$ & $0.66 \mathrm{~ns}$ \\
\hline
\end{tabular}

${ }^{\mathrm{z}}$ Levels of probability: $\mathrm{ns}=$ nonsignificant and $*=0.05$. 
occurred at 18, 24, 48, 72, and 96 hai for the -Si treatment and at 48,72 , and 96 hai for the + Si treatment.

\section{DISCUSSION}

Dallagnol et al. (14) used the lsil mutant and its wild-type counterpart, cv. Oochikara, to demonstrate that active Si uptake by the lateral roots of rice plants plays a key role in their resistance to brown spot. It was reported that $\mathrm{Si}$ concentration from both cv. Oochikara and the lsil mutant plants in the presence of Si increased in leaf tissue by 219 and $178 \%$, respectively, compared with when the plants were grown in the absence of this element. The components of host resistance, relative infection efficiency, AUBSPC, final lesion size, rate of lesion expansion,
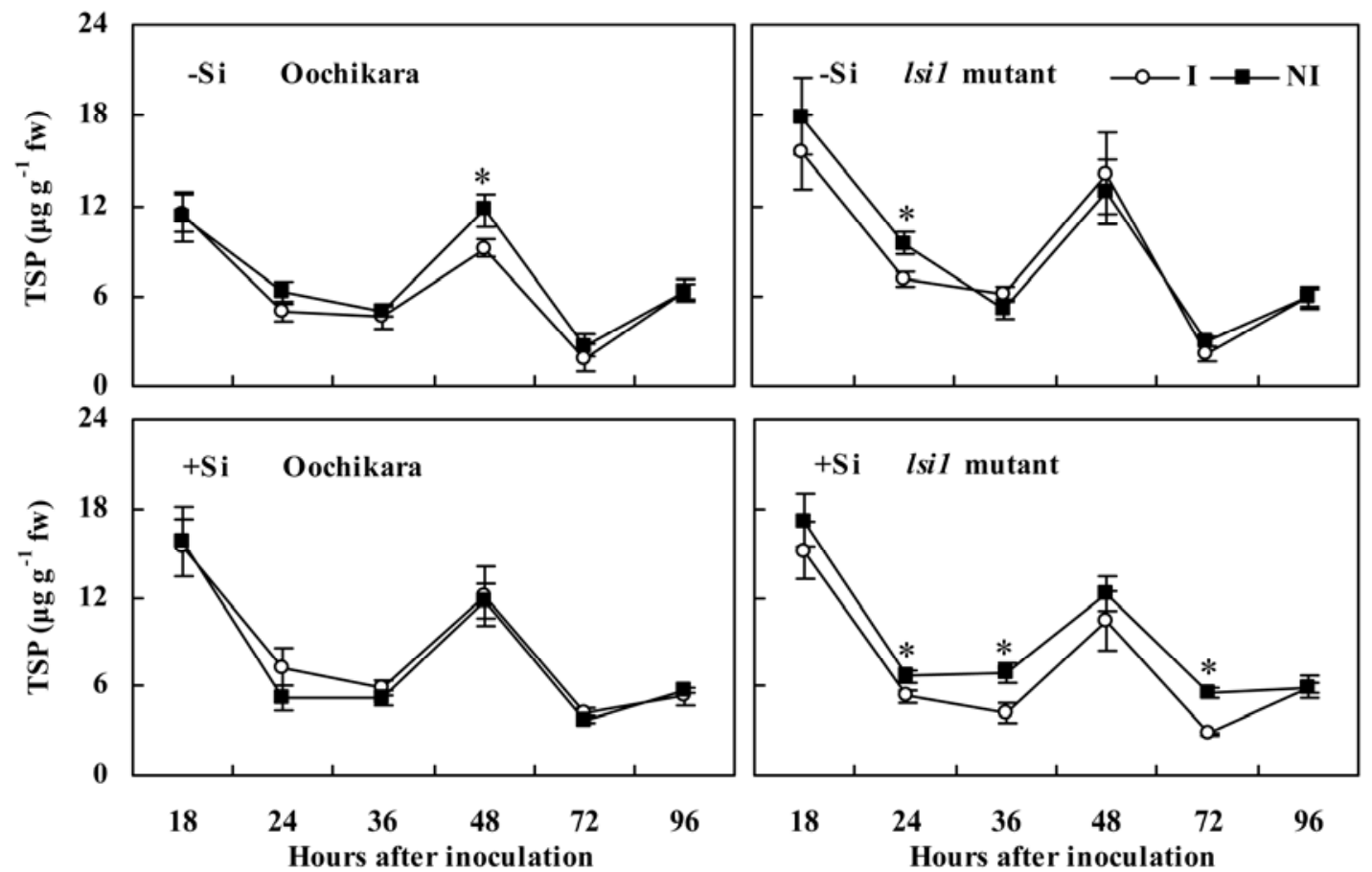

Fig. 6. Concentration of total soluble phenolics (TSP) in leaf tissue of rice plants from cv. Oochikara and the lsil mutant grown in hydroponic culture containing 0 or $2 \mathrm{mM}$ silicon $(-\mathrm{Si}$ or $+\mathrm{Si}$, respectively) and noninoculated (NI) or inoculated (I) with Bipolaris oryzae. Each point represents the mean of eight replications. Error bars represent standard deviation of the means. Means from NI and I treatments followed by an asterisk $\left(^{*}\right)$ are different $(P \leq 0.05)$ by $t$ test; fw $=$ fresh weight.
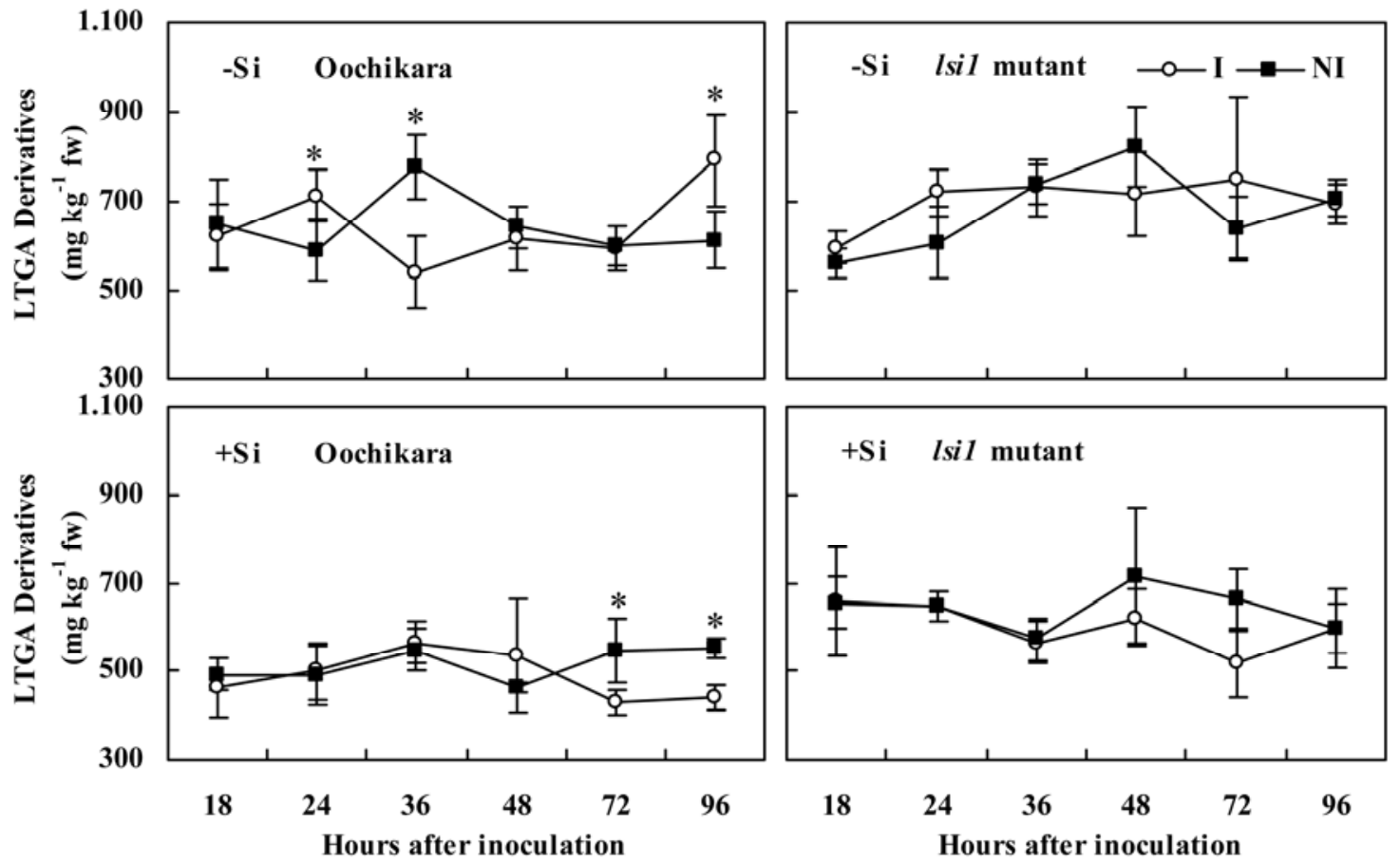

Fig. 7. Concentration of lignin and lignin-like polymers, determined as lignin-thioglycolic acid (LTGA) derivatives, in leaf tissue of rice plants from cv. Oochikara and the lsil mutant grown in hydroponic culture containing 0 or $2 \mathrm{mM}$ silicon (-Si or $+\mathrm{Si}$, respectively) and noninoculated (NI) or inoculated (I) with Bipolaris oryzae. Each point represents the mean of eight replications. Error bars represent standard deviation of the means. Means from NI and I treatments followed by an asterisk $(*)$ are different $(P \leq 0.05)$ by $t$ test; fw $=$ fresh weight. 
and area under lesion expansion progress curve were significantly reduced by $65,75,33,36$, and $35 \%$, respectively, for cv. Oochikara in the presence of Si. By contrast, for the $l s i l$ mutant, also in the presence of $\mathrm{Si}$, these components of resistance were only reduced by $40,50,12,21$, and $12 \%$, respectively, which indicated that a reduced $\mathrm{Si}$ concentration in leaf tissues affected the basal level of resistance to brown spot. In support of the data provided by Dallagnol et al. (14), the present study provides the first cyto- logical, physiological, and biochemical features associated with the increase in rice resistance to brown spot.

Taking into consideration that the progressive necrosis of rice leaf cells requires a continuous metabolic activity of $B$. oryzae (45), it is postulated that the higher number of brown epidermal cells on leaves of cv. Oochikara and the lsil mutant grown in the absence of Si resulted from unlimited fungal growth compared with what was obtained for plants supplied with $\mathrm{Si}$, where fungal
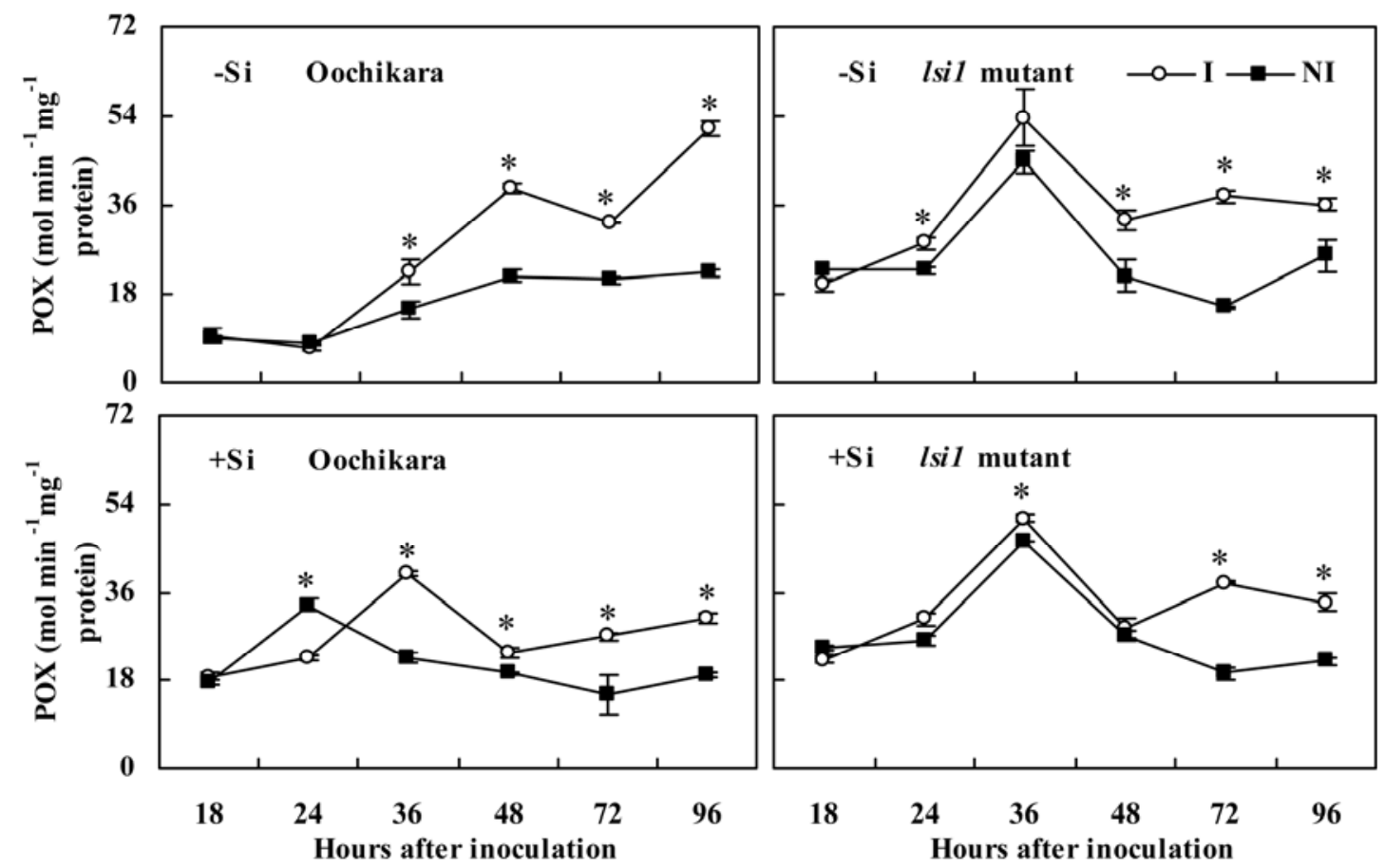

Fig. 8. Peroxidase (POX) activity in leaf tissue of rice plants from cv. Oochikara and the $l s i 1$ mutant grown in hydroponic culture containing 0 or $2 \mathrm{mM}$ silicon $(-\mathrm{Si}$ or $+\mathrm{Si}$, respectively) and noninoculated (NI) or inoculated (I) with Bipolaris oryzae. Each point represents the mean of eight replications. Error bars represent standard deviation of the means. Means from NI and I treatments followed by an asterisk $(*)$ are different $(P \leq 0.05)$ by $t$ test.
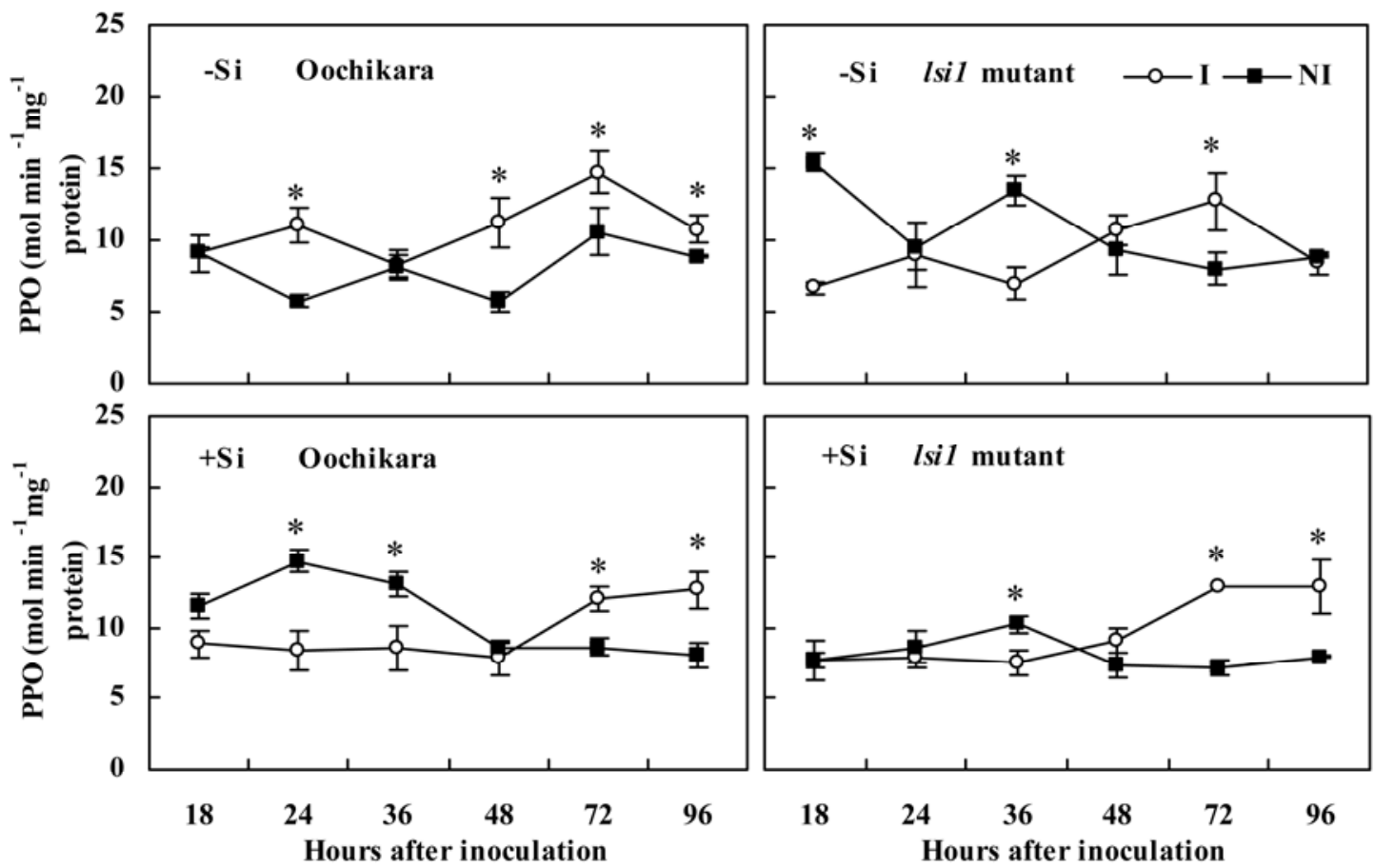

Fig. 9. Polyphenoloxidase (PPO) activity in leaf tissue of rice plants from cv. Oochikara and the lsil mutant grown in hydroponic culture containing 0 or $2 \mathrm{mM}$ silicon (-Si or $+\mathrm{Si}$, respectively) and noninoculated (NI) or inoculated (I) with Bipolaris oryzae. Each point represents the mean of eight replications. Error bars represent standard deviation of the means. Means from NI and I treatments followed by an asterisk (*) are different $(P \leq 0.05)$ by $t$ test. 
growth was greatly restricted. Therefore, it seems that, in areas of heavy Si deposition such as below the cuticle and also in the plant cell wall, a delay in fungal ingress and colonization provides the rice plant with enough time to activate mechanisms of defense. Menzies et al. (43) observed a negative correlation between $\mathrm{Si}$ content in leaf tissues of cucumber plants and several measures of pathogen growth, including leaf area covered by colonies of Sphaerotheca fuliginea, number of colonies per leaf, individual colony size, and germination of conidia produced on the leaves. The authors believed that the increased resistance of cucumber leaves to powdery mildew was associated with the reinforcement of epidermal cell walls by $\mathrm{Si}$.

The reduced growth of $B$. oryzae on leaf tissue of plants from cv. Oochikara and the lsil mutant was also associated with a lower concentration of MDA and less EL. The MDA produced during lipid peroxidation is an indicator of cellular damage that results in an increase in EL. It is well known that lipid peroxidation in the plasma membrane cell wall by reactive oxygen species is caused by the occurrence of any type of stress to the cells $(17,25)$ such as the damage by nonspecific toxins produced by $B$. oryzae. In the presence of $\mathrm{Si}$, the reduced concentration of MDA may be due to less toxin diffusion throughout leaf tissue associated with a more efficient antioxidant system to minimize the effect of this metabolite. According to Lima et al. (36), the increase in cell damage results from an imbalance between the production of reactive oxygen species and host defense mechanisms in favor of the former. It is known that host resistance against necrotrophic pathogens such as $B$. oryzae needs specific mechanisms of defense such as the production of enzymes that can detoxify the toxins produced by the pathogen $(33,64)$. In the case of $B$. oryzae, mesophyll cells collapse without direct contact with fungal hyphae, suggesting that the production of toxins and their diffusion occur before the fungus can reach the cells (19). During the infectious process, $B$. oryzae produces high levels of nonspecific toxins which are very deleterious to the rice cells (12). Among these toxins, ophiobolin A was shown to cause high loss of electrolytes and glucose in rice and maize cells, mainly related to an effect on calmodulins $(2,3,59)$. Ophiobolin A is important for B. oryzae infection (67). The high levels of lipid peroxidation, as indicated by the enhanced production of MDA, could cause an increase in host membrane permeability that, in turn, leads to more EL, especially at high disease severity, which can be confirmed by the high values obtained for AUBSPC from plants not supplied with $\mathrm{Si}$. Si has positive benefits to cellular protection, especially under salt stress (16). According to Gunes et al. (21), plasma membrane permeability and the concentration of MDA were reduced on barley leaves from plants grown in hydroponic solution containing $\mathrm{Si}$ and submitted to sodium and boron stress $(34,70)$. Si also has an effect on the activity of enzymes such as $\mathrm{H}^{+}$-ATPase on plants submitted to saline stress, suggesting that it can somehow affect the structure and the integrity of the plasma membrane (35). Indeed, $\mathrm{Si}$ can also increase the stability of lipids in the cellular membrane of rice plants submitted to both salinity and high temperatures (1).

The reduced lipid peroxidation in the plasma membrane of rice leaf cells of $+\mathrm{Si}$ plants in the initial stages of $B$. oryzae infection was due, at least in part, to more activity of POX. This became clear on leaves from cv. Oochikara and the lsi 1 mutant plants not supplied with $\mathrm{Si}$, where the reduction in the concentration of MDA at 36 hai coincided with an increase in POX activity. Rodrigues et al. (51) showed that POX transcripts increased during the course of infection of $P$. grisea in both incompatible and compatible interactions on rice plants supplied or not with $\mathrm{Si}$, presumably due to the participation of POX in the biosynthesis of lignin. Cucumber plants supplied with $\mathrm{Si}$ and inoculated with Podosphaera xanthii also showed an increase in the activity of POX compared with plants not supplied with this element (35).

In rice, resistance against blast was associated with the density of silicified cells in the leaf epidermis or the cuticle-silica double layer formed upon deposition and polymerization of monosilicic acid beneath the cuticle (28). However, Rodrigues et al. (51) pointed out that, although a decrease in the number of blast lesions possibly contributed to the fact that some appressoria from $P$. grisea cannot overcome the physical impediment offered by the cuticle-silica double layer, the presence of silica cells and silica
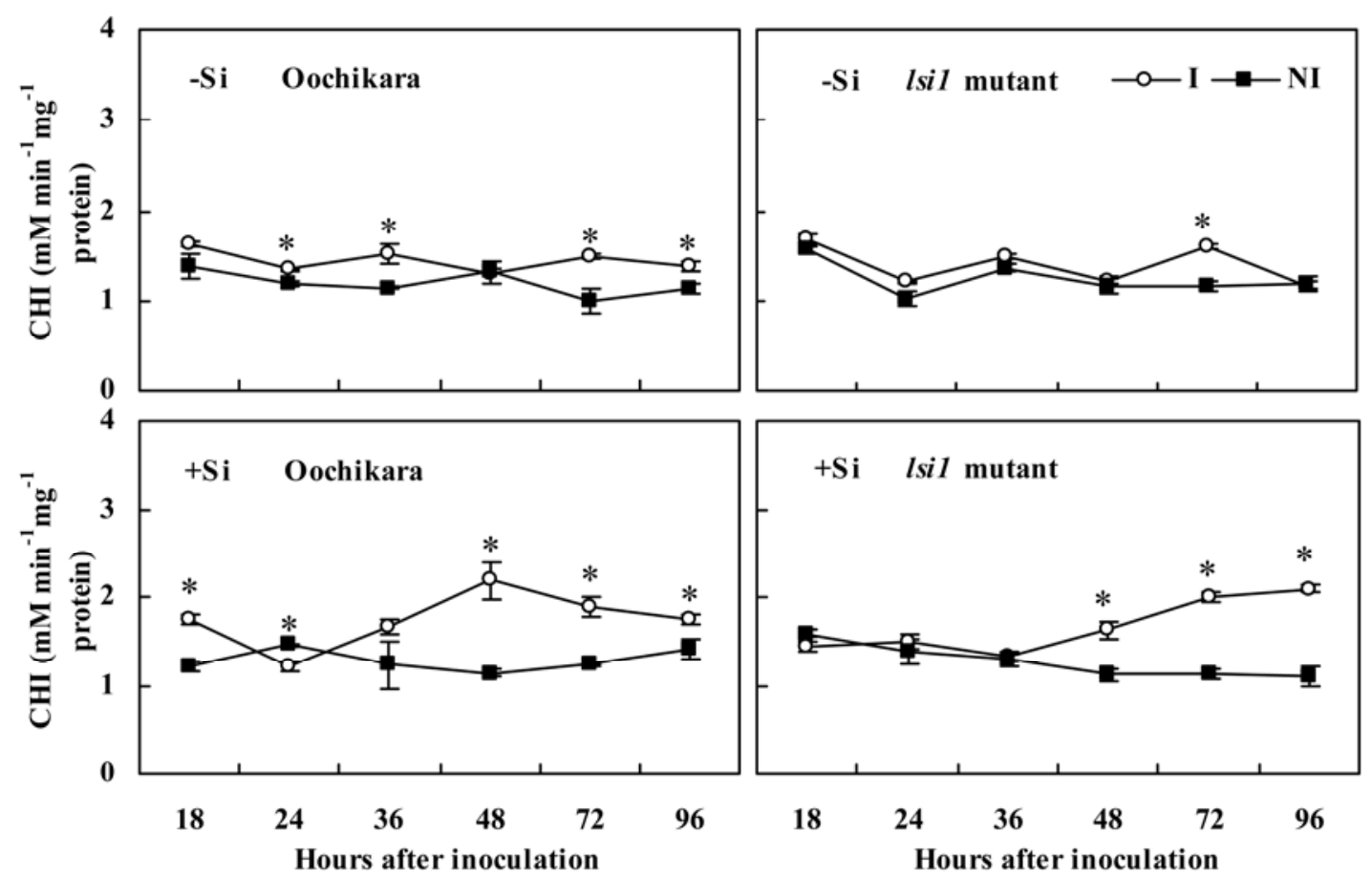

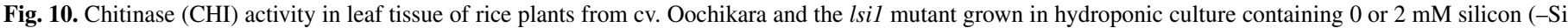

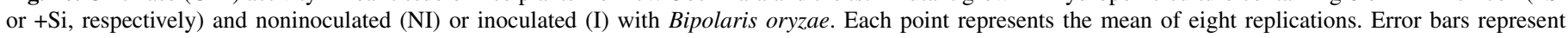
standard deviation of the means. Means from NI and I treatments followed by an asterisk $\left(^{*}\right)$ are different $(P \leq 0.05)$ by $t$ test. 
bodies that are not uniformly distributed in the adaxial epidermis of a rice leaf may allow fungus penetration and successful infection. Indeed, in a sequence of studies, the authors showed that rice resistance to blast was much more complex than a physical resistance promoted by the silicified cells. Plants supplied with $\mathrm{Si}$ produced more phenolics and momilactone phytoalexins, and increased activation of some PR genes, such as PR-1 and peroxidase $(49,51,52)$. Supplying $\mathrm{Si}$ to plants was shown to increase the concentration of phenolic compounds in response to pathogen attack $(5,43)$. The concentration of TSP was also associated with resistance of cv. Oochikara supplied with Si to brown spot more than in plants from the $l s i 1$ mutant regardless of the presence of $\mathrm{Si}$. The concentration of LTGA derivatives was also important to the resistance of plants from cv. Oochikara and the lsil mutant to brown spot, especially for the former. The low concentration of $\mathrm{Si}$ on leaf tissue of plants from the lsil mutant, even in the presence of $\mathrm{Si}$, affected the production of LTGA derivatives associated with an increase in the AUBSPC. It is well known that the fungitoxic effect of most phenolics is attributed mainly to their interaction with lipids or phospholipids, causing an increase in fungal membrane permeability, leakage of cell contents, and cytoplasm aggregation $(56,66)$. An array of phenolic compounds such as chlorogenic, $p$-coumaric, ferulic, salicylic, cinnamic, and caffeic acids are known to occur in rice as preformed compounds $(30,61)$. Changes in the composition and levels of these pre- or post-infectional phenolic compounds may have been modulated by $\mathrm{Si}$ to enhance rice resistance against infection by $B$. oryzae. The reduction in the concentration of TSP may be explained by the faster oxidation of these compounds by POX and PPO enzymes, which resulted in the high concentration of LTGA derivatives. Lignin biosynthesis begins in the plant cytosol with the synthesis of glycosylated monolignols from phenylalanine (8). Lignin is covalently linked to hemicellulose and, thereby, crosslinks different plant polysaccharides that confer mechanical strength to the cell wall (9) against the many lytic enzymes produced by pathogens during host tissue colonization. Rodrigues et al. (51) found that the accumulation of LTGA derivatives was biphasic in rice cvs. Katy and M201 inoculated with an isolate of $P$. grisea that resulted in an incompatible and a compatible interaction, respectively, regardless of whether the plants from these cultivars were supplied or not with $\mathrm{Si}$. The rate of lignin and lignin-like polymer accumulation, determined as LTGA derivatives, was much slower in the $+\mathrm{Si}$ than in the $-\mathrm{Si}$ plants of cv. M201 whereas, in cv. Katy, a difference between -Si and $+\mathrm{Si}$ plants was not observed. Rodrigues et al. (51) also reported a strong induction of POX transcripts following infection by Pyricularia grisea which corresponded to an increase in the concentration of LTGA derivatives. The impregnation of phenolic-like compounds in or beneath the rice cell walls may have contributed to the delay in colonization by $B$. oryzae by reinforcing and protecting the cell walls from the deleterious action of both degrading enzymes and toxins produced by the fungus which, together, are responsible for the intense leaf necrosis.

The enzymes POX and PPO are involved in host resistance because they are linked to the polymerization of phenolics that increase tissue lignification $(20,62)$. However, in the present study, the concentration of LTGA derivatives could not be associated with the activity of POX and PPO, especially the former. Therefore, the results suggest that the role played by POX in rice resistance to brown spot is more related to its antioxidant activity than to its involvement in the polymerization of phenolics to further increase the resistance of plant cell walls. The participation of PPO in rice resistance to brown spot was not clear for both cv. Oochikara and the lsil mutant plants regardless of $\mathrm{Si}$ supply. This may indicate that the participation of the oxidative metabolism of phenolics was of less importance than the concentration of LTGA derivatives in increasing the resistance of plants to brown spot, especially those from cv. Oochikara. The high concentration of LTGA derivatives in leaves from cv. Oochikara and the lsil mutant not supplied with $\mathrm{Si}$ can be attributed to the high values of AUBSPC compared with plants supplied with Si. However, the high concentration of LTGA derivatives was not sufficient to decrease disease progress as indicated by the AUBSPC. The activities of POX and CHI were higher in inoculated plants from cv. Oochikara and the lsil mutant supplied with $\mathrm{Si}$. The reduction in POX activity on leaves from cv. Oochikara supplied with Si concurred with an increase in $\mathrm{CHI}$ activity. Plant chitinases are important enzymes in defense systems not only because they inhibit the growth of some fungi, such as $B$. oryzae, by causing cell wall dissolution, but also because the release of chitin oligomers can potentially elicit other mechanisms of host defense. According to Rodrigues et al. (49), chitinases were not an important mechanism of rice defense to $P$. grisea because the pattern of chitin localization over fungal cell walls in tissues of $-\mathrm{Si}$ and $+\mathrm{Si}$ plants of cv. M201 was very similar in uniformity and density.

Results from the current study bring novel evidence of the involvement of $\mathrm{Si}$ in a more complex defense mechanism than simply the formation of a physical barrier to prevent or delay $B$. oryzae penetration. The results also highlight the importance of active Si uptake by rice to achieve a desirable level of resistance to brown spot.

\section{ACKNOWLEDGMENTS}

This study was partially financed by CAPES, CNPq, and FAPEMIG. We thank CNPq for the fellowship for F. A. Rodrigues and F. M. DaMatta; CNPq for supporting L. J. Dallagnol; A. S. Prabhu for kindly providing the isolate of $B$. oryzae; G. H. Korndörfer for Si analysis; and J. F. Ma (Research Institute for Bioresources, Okayama University, Japan) for providing the rice seed from $\mathrm{cv}$. Oochikara and the lsil mutant.

\section{LITERATURE CITED}

1. Agarie, S., Hanaoka, N., Ueno, O., Miyazaki, A., Kubota, F., Agata, W., and Kaufman, P. B. 1998. Effects of silicon on tolerance to water deficit and heat stress in rice plants (Oryza sativa L.) monitored by electrolyte leakage. Plant Prod. Sci. 1:96-103.

2. Au, T. K., Chick, W., and Leung, P. C. 2000. Initial kinetics of the inactivation of calmodulin by the fungal toxin ophiobolin A. Int. J. Biochem. Cell Biol. 32:1173-1182.

3. Au, T. K., and Leung, P. C. 1998. Identification of the binding and inhibition sites in the calmodulin molecule for ophiobolin A by sitedirected mutagenesis. Plant Physiol. 118:965-73.

4. Barber, M. S., and Ride, J. P. 1988. A quantitative assay for induced lignification in wounded wheat leaves and its use to survey potential elicitors of the response. Physiol. Mol. Plant Pathol. 32:185-197.

5. Bélanger, R. R., Benhamou, N., and Menzies, J. G. 2003. Cytological evidence of an active role of silicon in wheat resistance to powdery mildew (Blumeria graminis f. sp. tritici). Phytopathology 93:402-412.

6. Brunings, A. M., Datnoff, L. E., Ma, J. F., Mitani, N., Nagamura, Y., Rathinasabapathi, B., and Kirst, M. 2009. Differential gene expression of rice in response to silicon and rice blast fungus Magnaporthe oryzae. Ann. Appl. Biol. 155:161-170.

7. Cakmak, L., and Host, W. J. 1991. Effect of aluminum on lipid peroxidation, superoxide dismutase, catalase, and peroxide activity in root tip of soybean (Glycine max). Plant Physiol. 83:463-468.

8. Campbell, M. M., and Sederoff, R. R. 1996. Variation in lignin content and composition. Plant Physiol. 110:3-13.

9. Chabannes, M., Ruel, K., Yoshinaga, A., Chabbert, B., Jauneau, A., Joseleau, J. P., and Boudet, A. M. 2001. In situ analysis of lignins in transgenic tobacco reveals a differential impact of individual transformations on the spatial patterns of lignin deposition at the cellular and subcellular levels. Plant J. 28:271-282.

10. Chain, F., Côté-Beaulieu, C., Belzile, F., Menzies, J. G., and Bélanger, R. R. 2009. A comprehensive transcriptomic analysis of the effect of silicon on wheat plants under control and pathogen stress conditions. Mol. PlantMicrobe Interact. 22:1323-1330.

11. Chance, B., and Maehley, A. C. 1955. Assay of catalases and peroxidases. Methods Enzymol. 2:764-775. 
12. Cocucci, S. M., Morguttia, S., Cocuccib, M., and Gianani, L. 1983. Effects of ophiobolin A on potassium permeability, transmembrane electrical potential and proton extrusion in maize roots. Plant Sci. Lett. 32:9-16.

13. Cunningham, J. L. 1972. A miracle mounting fluid for permanent wholemounts of microfungi. Mycologia 64:906-911.

14. Dallagnol, L. J., Rodrigues, F. Á., Mielli, M. V. B., Ma, J. F., and Datnoff, L. E. 2009. Defective active silicon uptake affects some components of rice resistance to brown spot. Phytopathology 99:116-121.

15. Datnoff, L. E., Raid, R. N., Snyder, G. H., and Jones, D. B. 1991. Effect of calcium silicate on blast and brown spot intensities and yields of rice. Plant Dis. 75:729-732.

16. Datnoff, L. E., Rodrigues, F. Á., and Seebold, K. W. 2007. Silicon and plant disease. Pages 233-246 in: Mineral Nutrition and Plant Disease. L. E. Datnoff, W. H. Elmer, and D. M. Huber, eds. The American Phytopathological Society, St. Paul, MN.

17. Fu, J., and Huang, B. 2001. Involvement of antioxidants and lipid peroxidation in the adaptation of two cool-season grasses to localized drought stress. Environ. Exp. Bot. 45:105-114.

18. Gangopadhyay, S., and Chatopadhyay, S. B. 1974. Total silica and brown spot disease development of rice under varying levels of nitrogen. Curr. Sci. 44:91-94.

19. Goto, I. 1958. Effects of the culture-filtrate of the causal fungi upon the plant: Observation by the sheath-inoculation methods. Pages 237-388 in: Studies on the Helminthosporium Leaf Blight of Rice Plants. Vol. 2. Agricultural Sciences, Yamagata, Japan.

20. Grisebach, H. 1981. Lignin. Pages 451-478 in: The Biochemistry of Plants. E. E. Conn, ed. Academic Press, New York.

21. Gunes, A., Inal, A., Bagci, E. G., and Coban, S. 2007. Silicon-mediated changes on some physiological and enzymatic parameters symptomatic of oxidative stress in barley grown in sodic-B toxic soil. J. Plant Physiol. 164:807-811.

22. Harman, G. E., Hayes, C. K., Lorito, M., Broadway, R. M., Pietro, A. D., Peterbauer, C., and Tronsmo, A. 1993. Chitinolytic enzymes of Trichoderma harzianum: Purification of chitobiosidase and endochitinase. Phytopathology 83:313-318.

23. Hoagland, D. R., and Arnon, D. I. 1950. The water culture method for growing plant without soil. Calif. Agric. Exp. Stn. Circ. 347:1-32.

24. IRRI. 1996. Standard Evaluation System for Rice, 4th ed. International Rice Research Institute, Manila, Philippines.

25. Iturbe-Ormaetxe, I., Escuredo, P., Arrese-Igor, C., and Becana, M. 1998. Oxidative damage in pea plants exposed to water deficit or paraquat. Plant Physiol. 116:173-181.

26. Kar, M., and Mishra, D. 1976. Catalase, peroxidase, and polyphenoloxidase activities during rice leaf senescence. Plant Physiol. 57:315-319.

27. Kaur, P., and Padmanadhan, S. Y. 1974. Control of helminsthosporium disease of rice with soil amendments. Curr. Sci. 43:78-79.

28. Kim, S. G., Kim, K. W., Eun, W. P., and Choi, D. 2002. Silicon-induced cell wall fortification of rice leaves: A possible cellular mechanism of enhanced host resistance to blast. Phytopathology 92:1095-1103.

29. Kohls, C. L., Percich, J. A., and Huot, C. M. 1987. Wild rice yield losses associated with growth-stage-specific fungal brown spot epidemics. Plant Dis. 71:419-422.

30. Kuwatsuka, S., and Oshima, Y. 1962. Studies on polyphenols of rice plants, part II. J. Agric. Chem. Soc. Jpn. 35:71-74.

31. Lanna, A. C., Oliveira, M. G. A., Barros, E. G., and Moreira, M. A. 1996. Kinetic parameters of leaf lipoxygenases pool from normal soybean genotypes and from a line devoid of seed lipoxygenases. Rev. Bras. Fisiol. Veg. 8:87-92.

32. Lee, F. N. 1992. Brown spot. Pages 14-17 in: Compendium of Rice Diseases. R. K. Webster, and P. S. Gunnell, eds. The American Phytopathological Society, St. Paul, MN.

33. Leung, P. C., Taylor, W. A., Wang, J. H., and Tipton, C. L. 1984. Ophiobolin A - a natural product inhibitor of calmodulin. J. Biol. Chem. 259:2742-2747.

34. Liang, Y., Chen, Q., Liu, Q., Zhang, W., and Ding, R. 2003. Exogenous silicon $(\mathrm{Si})$ increases antioxidant enzyme activity and reduces lipid peroxidation in roots of salt-stressed barley (Hordeum vulgare L.). J. Plant Physiol. 160:1157-1164.

35. Liang, Y., Zhang, W., Chenc, Q., and Ding, R. 2005. Effects of silicon on $\mathrm{H}^{+}$-ATPase and $\mathrm{H}^{+}$-PPase activity, fatty acid composition and fluidity of tonoplast vesicles from roots of salt-stressed barley (Hordeum vulgare L.). Environ. Exp. Bot. 53:29-37.

36. Lima, A. L. S., DaMatta, F. M., Pinheiro, H. A., Totola, M. R., and Loureiro, M. E. 2002. Photochemical responses and oxidative stress in two clones of Coffea canephora under water deficit conditions. Environ. Exp. Bot. 47:239-247.

37. Ma, J. F., and Takahashi, E. 2002. Soil, Fertilizer, and Plant Silicon Research in Japan, 1st ed. Elsevier Science, Amsterdam.

38. Ma, J. F., Tamai, K., Ichii, M., and Wu, G. F. 2002. A rice mutant defective in Si uptake. Plant Physiol. 130:2111-2117.

39. Ma, J. F., and Yamaji, N. 2006. Silicon uptake and accumulation in higher plants. Trends Plant Sci. 11:392-397.

40. Ma, J. F., and Yamaji, N. 2008. Functions and transport of silicon in plants. Cell. Mol. Life Sci. 65:3049-3057

41. Ma, J. F., Yamaji, N., Mitani, N., Tamai, K., Konishi, S., Fujiwara, T., Katsuhara, M., and Yano, M. 2007. An efflux transporter of silicon in rice. Nature 448:209-213.

42. Matsuo, T., and Hoshikama, K. 1993. Science of the rice plant morphology. Food Agric. Policy Res. Cent. Tokyo.

43. Menzies, J. G., Ehret, D. L., Glass, A. D. M., and Samuels, A. L. 1991. The influence of silicon on cytological interactions between Sphaerotheca fuliginea and Cucumis sativus. Physiol. Mol. Plant Pathol. 39:403-414.

44. Nanda, H. P., and Gangopadhyay, S. 1984. Role of silicated cells in rice leaf on brown spot disease incidence by Bipolaris oryzae. Int. J. Trop. Plant Dis. 2:89-98.

45. Ou, S. H. 1985. Rice Diseases, 2nd ed. Commonwealth Mycological Institute, Kew, U.K

46. Peixoto, P. H. P., Cambraia, J., Sant'anna, R., Mosquim, P. R., and Moreira, M. A. 1999. Aluminum effects on lipid peroxidation and on the activities of enzymes of oxidative metabolism in sorghum. Rev. Bras. Fisiol. Veg. 11:137-143.

47. Rémus-Borel, W., Menzies, J. G., and Bélanger, R. R. 2009. Aconitate and methyl aconitate are modulated by silicon in powdery mildewinfected wheat plants. J. Plant Physiol. 166:1413-1422

48. Roberts, W. K., and Selitrennikoff, C. P. 1988. Plant and bacterial chitinases differ in antifungal activity. J. Gen. Microbiol. 134:169-176.

49. Rodrigues, F. A., Benhamou, N., Datnoff, L. E., Jones, J. B., and Bélanger, R. R. 2003. Ultrastructural and cytochemical aspects of silicon mediated rice blast resistance. Phytopathology 93:535-546.

50. Rodrigues, F. A., Datnoff, L. E., Korndörfer, G. H., Seebold, K. W., and Rush, M. C. 2001. Effect of silicon and host resistance on sheath blight development in rice. Plant Dis. 85:827-832.

51. Rodrigues, F. A.; Jurick, W. M., Datnoff, L. E., Jones, J. B., and Rollins, J. A. 2005. Silicon influences cytological and molecular events in compatible and incompatible rice-Magnaporthe grisea interactions. Physiol. Mol. Plant Pathol. 66:144-159.

52. Rodrigues, F. A., McNally, D. J., Datnoff, L. E., Jones, J. B., Labbé, C., Benhamou, N., Menzies, J. G., and Bélanger, R. R. 2004. Silicon enhances the accumulation of diterpenoid phytoalexins in rice: A potential mechanism for blast resistance. Phytopathology 94:177-183.

53. Savant, N. K., Snyder, G. H., and Datnoff, L. E. 1997. Silicon management and sustainable rice production. Adv. Agron. 58:151-199.

54. Seebold, K. W., Kucharek, T. A., Datnoff, L. E., Correa-Victoria, J. F., and Marchetti, M. A. 2001. The influence of silicon on components of resistance to blast in susceptible, partially resistant, and resistant cultivars of rice. Phytopathology 91:63-69.

55. Shaner, G., and Finney, R. E. 1977. The effect of nitrogen fertilization on the expression of slow-mildewing resistance in knox wheat. Phytopathology 70:1183-1186.

56. Southerton, S. G., and Deverall, B. J. 1990. Histochemical and chemical evidence for lignin accumulation during the expression of resistance to leaf rust fungi in wheat. Physiol. Mol. Pathol. 36:483-494.

57. Takahashi, E., and Hino, K. 1978. Effect of different Si forms on silicic acid uptake. J. Sci. Soil Manure 33:453-455.

58. Takahashi, Y. 1967. Nutritional studies on development of Helminthosporium leaf spot. Pages 157-170 in: Proc. Symp. Rice Dis. and their Control by Growing Resistant Varieties and other Measures. Agriculture, Forestry, and Fisheries Research Council, Tokyo.

59. Tipton, C. L., Paulsen, P. V., and Betts, R. E. 1977. Effects of ophiobolin A on ion leakage and hexose uptake by maize roots. Plant Physiol. 59:907-910.

60. Tullis, E. C. 1935. Histological studies of rice leaves infected with Helminthosporium oryzae. J. Agric. Res. 50:82-90.

61. Varga, M. 1970. Correlation between the phenol content, polyphenol oxidase and peroxidase activity and the growth of rice seedlings with particular respect to flooding conditions. Riso 19:353-360.

62. Vidhyasekaran P. 1988. Physiology of Disease Resistance in Plants. Vol. 1. CRC Press, Inc., Boca Raton, FL.

63. Vidhyasekaran, P., Borromeo, E. S., and Mew, T. W. 1992. Helminthosporium oryzae toxin suppresses phenol metabolism in rice plants and aids pathogen colonization. Physiol. Mol. Plant Pathol. 41:307-315.

64. Walton, J. D. 1996. Host-selective toxins: Agents of compatibility. Plant Cell 8:1723-1733.

65. Warburg, O., and Christian W. 1941. Isohering und kristallisation des gõrungs ferments enolase. Biochem. Zool. 310:384-421.

66. Weete, E. R. 1980. Lipid Biochemistry of Fungi and other Organisms. Plenum Press, New York.

67. Xiao, J. Z., Tsuda, M., Doke, N., and Nishimura, S. 1991. Phytotoxins produced by germinating spores of Bipolaris oryzae. Phytopathology 
81:58-64.

68. Yamaji, I., Mitatni, N., and Ma, J. F. 2008. A transporter regulating silicon distribution in rice shoots. Plant Cell 20:1381-1389.

69. Yoshida, S., Ohnishi, Y., and Kitagishi, K. 1962. Chemical forms, mobility and deposition of silicon in rice plant. Soil Sci. Plant Nutr. 8: $15-21$.
70. Zhu, Z., Wei, G., Li, J., Qian, Q., and Yu, J. 2004. Silicon alleviates salt stress and increases antioxidant enzymes activity in leaves of salt-stressed cucumber (Cucumis sativus L.). Plant Sci. 167:527-533.

71. Zieslin, N., and Ben-Zaken, R. 1993. Peroxidase activity and presence of phenolic substances in peduncles of rose flowers. Plant Physiol. Biochem. 31:333-339. 